\title{
Mass-based hygroscopicity parameter interaction model and measurement of atmospheric aerosol water uptake
}

\author{
E. Mikhailov ${ }^{1,2}$, S. Vlasenko ${ }^{2}$, D. Rose $^{1}$, and U. Pöschl ${ }^{1}$ \\ ${ }^{1}$ Multiphase Chemistry and Biogeochemisty Departments, Max Planck Institute for Chemistry, Mainz, Germany \\ ${ }^{2}$ Atmospheric Physics Department, Institute of Physics, St. Petersburg State University, St. Petersburg, Russia \\ Correspondence to: E. Mikhailov (eugene.mikhailov@paloma.spbu.ru)
}

Received: 21 October 2011 - Published in Atmos. Chem. Phys. Discuss.: 18 November 2011

Revised: 22 November 2012 - Accepted: 17 December 2012 - Published: 21 January 2013

\begin{abstract}
In this study we derive and apply a mass-based hygroscopicity parameter interaction model for efficient description of concentration-dependent water uptake by atmospheric aerosol particles with complex chemical composition. The model approach builds on the single hygroscopicity parameter model of Petters and Kreidenweis (2007). We introduce an observable mass-based hygroscopicity parameter $\kappa_{\mathrm{m}}$ which can be deconvoluted into a dilute hygroscopicity parameter $\left(\kappa_{\mathrm{m}}^{0}\right)$ and additional self- and cross-interaction parameters describing non-ideal solution behavior and concentration dependencies of single- and multi-component systems.

For reference aerosol samples of sodium chloride and ammonium sulfate, the $\kappa_{\mathrm{m}}$-interaction model (KIM) captures the experimentally observed concentration and humidity dependence of the hygroscopicity parameter and is in good agreement with an accurate reference model based on the Pitzer ion-interaction approach (Aerosol Inorganic Model, AIM). Experimental results for pure organic particles (malonic acid, levoglucosan) and for mixed organic-inorganic particles (malonic acid - ammonium sulfate) are also well reproduced by KIM, taking into account apparent or equilibrium solubilities for stepwise or gradual deliquescence and efflorescence transitions.

The mixed organic-inorganic particles as well as atmospheric aerosol samples exhibit three distinctly different regimes of hygroscopicity: (I) a quasi-eutonic deliquescence $\&$ efflorescence regime at low-humidity where substances are just partly dissolved and exist also in a non-dissolved phase, (II) a gradual deliquescence \& efflorescence regime at intermediate humidity where different solutes undergo gradual dissolution or solidification in the aqueous phase; and (III) a dilute regime at high humidity where the solutes are fully dissolved approaching their dilute hygroscopicity.
\end{abstract}

For atmospheric aerosol samples collected from boreal rural air and from pristine tropical rainforest air (secondary organic aerosol) we present first mass-based measurements of water uptake over a wide range of relative humidity (1$99.4 \%$ ) obtained with a new filter-based differential hygroscopicity analyzer (FDHA) technique. For these samples the concentration dependence of $\kappa_{\mathrm{m}}$ can be described by a simple KIM model equation based on observable mass growth factors and a total of only six fit parameters summarizing the combined effects of the dilute hygroscopicity parameters, self- and cross-interaction parameters, and solubilities of all involved chemical components. One of the fit parameters represents $\kappa_{\mathrm{m}}^{0}$ and can be used to predict critical dry diameters for the activation of cloud condensation nuclei (CCN) as a function of water vapor supersaturation according to Köhler theory. For sodium chloride and ammonium sulfate reference particles as well as for pristine rainforest aerosols consisting mostly of secondary organic matter, we obtained good agreement between the KIM predictions and measurement data of $\mathrm{CCN}$ activation.

The application of KIM and mass-based measurement techniques shall help to bridge gaps in the current understanding of water uptake by atmospheric aerosols: (1) the gap between hygroscopicity parameters determined by hygroscopic growth measurements under sub-saturated conditions and by $\mathrm{CCN}$ activation measurements at water vapor supersaturation, and (2) the gap between the results of simplified single parameter models widely used in atmospheric or climate science and the results of complex multi-parameter ionand molecule-interaction models frequently used in physical chemistry and solution thermodynamics (e.g., AIM, E-AIM, ADDEM, UNIFAC, AIOMFAC). 


\section{Introduction}

The interaction of aerosol particles with water vapor is among the central issues of current research in atmospheric and climate science, and numerous studies have investigated the hygroscopicity of aerosol particles and their ability to serve as cloud condensation nuclei (CCN). Köhler theory is the main tool to describe the hygroscopic growth of particles as a function of relative humidity (e.g., Pruppacher and Klett, 2000; Seinfeld and Pandis, 2006), and various types of Köhler models have been developed and applied for the analysis of laboratory and field measurement results as well as in numerical models of the atmosphere and climate (e.g., Junge and McLaren, 1971; Fitzgerald, 1973, Shulman et al., 1996; Kulmala et al., 1997; Laaksonen et al., 1998, Raymond and Pandis, 2003; Bilde and Svenningsson, 2004; Mikhailov et al., 2004, 2009; Huff Hartz et al., 2005; McFiggans et al., 2006; Svenningsson et al., 2006; Rose et al., 2008; and references therein).

A central aim of hygroscopicity measurements and Köhler model studies is to relate the critical supersaturation of $\mathrm{CCN}$ activation to the hygroscopic growth factors observed at subsaturated conditions (e.g., Rissler et al., 2004; Kreidenweis et al., 2005; Mochida et al., 2006; Petters and Kreidenweis, 2007; Wex et al., 2008; Gunthe et al., 2009; Petters et al., 2009; Good et al., 2010a, b; Irwin et al., 2010; Roberts et al., 2010; Cerully et al., 2011; Duplissy et al., 2011; Fors et al., 2011; Metzger et al., 2012; and references therein). For this purpose, Petters and Kreidenweis (2007) proposed a single-parameter Köhler model where the hygroscopicity parameter $\kappa$ provides a volume-based measure of aerosol water uptake characteristics and CCN activity. For water soluble organic and inorganic compounds, the relative differences between $\kappa$ values derived from $\mathrm{CCN}$ and growth factor measurements are usually less than $30 \%$ and can be explained by non-ideal behavior of concentrated solutions (e.g., Wex et al., 2008; Mikhailov et al., 2009). For particles containing sparingly soluble compounds, however, the differences can increase by a factor of 5 or more (Petters and Kreidenweis, 2007). To bridge the gap between $\kappa$ values observed under subsaturated and supersaturated conditions, Petters and Kreidenweis (2008) proposed a pseudo-two-component $\kappa$-Köhler model where sparingly soluble compounds gradually enter the solution with increasing dilution and relative humidity. The practical applicability of volume based hygroscopicity models, however, is often limited by deviations from volumeadditivity and by the effects of capillary condensation and restructuring of porous and irregularly shaped particles (e.g., Krämer et al., 2000; Mikhailov et al., 2004, 2009; Gysel et al., 2004; Sjogren et al., 2007; Zardini et al., 2008; Wang et al., 2010).
Detailed thermodynamic models that describe the water uptake of aqueous solutions and aerosols are usually massbased rather than volume-based and require multiple input parameters for every chemical species involved. For example, seven parameters are used to describe a simple $\mathrm{NaCl}$ particle with the rigorous Aerosol Inorganic Model (AIM; Clegg et al., 1998; Wexler and Clegg, 2002; http://www.aim.env. uea.ac.uk/aim/aim.php). Other advanced models like the Extended Aerosol Inorganic Model (E-AIM; Clegg et al., 2001), the Aerosol Diameter Dependent Equilibrium Model (ADDEM, Topping et al., 2005a, b), the Universal Quasichemical Functional Group Activity Coefficients model (UNIFAC; Fredenslund et al., 1975; Hansen et al., 1991), the Aerosol Inorganic-Organic Mixtures Functional Groups Activity Coefficients model (AIOMFAC; Zuend et al., 2008, 2011) and related approaches referenced in the above studies typically also require four or more semi-empirical parameters for single solute systems plus additional interaction parameters for multi-component systems. Application of these complex thermodynamic models to atmospheric aerosols containing a multitude of unspeciated organic compounds remains difficult, especially at low relative humidity (RH) (Petters and Kreidenweis, 2007; Tong et al., 2008).

In this study we introduce a mass-based hygroscopicity parameter $\kappa_{\mathrm{m}}$ building on the single hygroscopicity parameter of Petters and Kreidenweis (2007), and we develop a $\kappa_{\mathrm{m}}$ interaction model (KIM), which describes the non-ideal solution behavior and concentration dependence of single- and multi-component systems with a small number of parameters that can be determined by fitting of measurement data. We demonstrate that the KIM approach can capture and reproduce the characteristics of water uptake by reference substances as well as atmospheric aerosol samples under suband supersaturated conditions.

\section{Theory}

\subsection{Volume-based hygroscopicity parameter $\kappa_{\mathrm{v}}$}

The Köhler theory relates the water activity $\left(a_{\mathrm{w}}\right)$, the partial molar volume of water $\left(\bar{V}_{\mathrm{w}}\right)$, the surface tension $(\sigma)$, and the diameter $(D)$ of a spherical aqueous droplet under equilibrium conditions to the water vapor saturation of the surrounding gas phase $\left(s_{\mathrm{W}}=\mathrm{RH} / 100 \%\right)$ (e.g., Pruppacher and Klett, 2000; Seinfeld and Pandis, 2006):

$s_{\mathrm{w}}=a_{\mathrm{w}} \exp \left(\frac{4 \sigma \bar{V}_{\mathrm{w}}}{R T D}\right)$,

where $R$ is the universal gas constant and $T$ is the temperature. Note that all frequently used symbols used in this manuscript are also explained in Table 1.

According to Petters and Kreidenweis (2007), the hygroscopic growth of aerosol particles can be efficiently approximated by a simplified version of Eq. (1), the so-called $\kappa_{\mathrm{v}^{-}}$ Köhler equation: 
Table 1. Frequently used symbols.

\begin{tabular}{|c|c|c|}
\hline Symbol & SI Unit & Quantity \\
\hline$a_{\mathrm{W}}$ & & water activity \\
\hline$C_{\mathrm{m}}$ & $\mathrm{kg} \mathrm{kg}^{-1}$ & solubility (gram solute per gram water) \\
\hline$C_{\mathrm{m}}^{\mathrm{eu}}$ & $\mathrm{kg} \mathrm{kg}^{-1}$ & eutonic solubility (gram solute per gram water) \\
\hline$C_{\mathrm{m}, i}^{\mathrm{ap}}$ & $\mathrm{kg} \mathrm{kg}^{-1}$ & apparent solubility (gram solute per gram water) \\
\hline$c_{\mathrm{m}, i}$ & $\mathrm{~kg} \mathrm{~kg}^{-1}$ & mass concentration (gram solute per gram water) \\
\hline$D$ & $\mathrm{~m}$ & diameter of aqueous solution droplet \\
\hline$D_{\mathrm{d}}$ & $\mathrm{m}$ & diameter of dry aerosol particle \\
\hline$D_{\mathrm{d}, \mathrm{c}}$ & $\mathrm{m}$ & critical dry diameter of $\mathrm{CCN}$ activation \\
\hline$f_{i}$ & & mass fraction of individual component in particulate matter \\
\hline$G_{\mathrm{D}}$ & & diameter growth factor \\
\hline$G_{\mathrm{m}}$ & & mass growth factor \\
\hline$J$ & & van't Hoff factor \\
\hline$m_{\mathrm{d}}$ & $\mathrm{kg}$ & mass of the dry solute in aqueous droplet \\
\hline$M_{\mathrm{W}}$ & $\mathrm{kg} \mathrm{mol}^{-1}$ & molar mass of pure water \\
\hline$m_{\mathrm{W}}$ & $\mathrm{kg}$ & mass of the water in aqueous droplet \\
\hline$R$ & $\mathrm{~J} \mathrm{~K}^{-1} \mathrm{~mol}^{-1}$ & universal gas constant \\
\hline$s_{\mathrm{W}}$ & & water vapor saturation ratio \\
\hline$S_{\mathrm{W}}$ & $\%$ & water vapor supersaturation \\
\hline$s_{\mathrm{W}, \mathrm{c}}$ & & critical water vapor saturation ratio \\
\hline$T$ & $\mathrm{~K}$ & temperature \\
\hline$\alpha_{i j}, \alpha_{i i}$ & & cross- and self-interaction coefficients \\
\hline$\kappa_{\mathrm{V}}$ & & volume-based hygroscopicity parameter \\
\hline$\kappa_{\mathrm{m}}$ & & mass-based hygroscopicity parameter \\
\hline$\kappa_{\mathrm{m}}^{0}$ & & mass-based dilute hygroscopicity \\
\hline$\mu$ & $\mathrm{mol} \mathrm{kg}^{-1}$ & molality (mole solute per kilogram water) \\
\hline$\rho_{\mathrm{d}}$ & $\mathrm{kg} \mathrm{m}^{-3}$ & density of dry particle material \\
\hline$\rho_{\mathrm{W}}$ & $\mathrm{kg} \mathrm{m}^{-3}$ & density of pure water \\
\hline$\sigma$ & $\mathrm{J} \mathrm{m}^{-2}$ & surface tension of solution droplet \\
\hline$\sigma_{\mathrm{W}}$ & $\mathrm{J} \mathrm{m}^{-2}$ & surface tension of pure water \\
\hline $\mathrm{RH}_{\mathrm{d}}$ & $\%$ & deliquescence relative humidity of individual component \\
\hline $\mathrm{RH}_{\mathrm{e}}$ & $\%$ & efflorescence relative humidity of individual component \\
\hline
\end{tabular}

$$
\begin{aligned}
s_{\mathrm{w}} & \approx a_{\mathrm{w}} \exp \left(\frac{4 \sigma_{\mathrm{w}} M_{\mathrm{w}}}{R T \rho_{\mathrm{w}} D}\right) \\
& =\left[\frac{\kappa_{\mathrm{v}}}{G_{\mathrm{D}}^{3}-1}+1\right]^{-1} \exp \left(\frac{4 \sigma_{\mathrm{w}} M_{\mathrm{w}}}{R T \rho_{\mathrm{w}} G_{\mathrm{D}} D_{\mathrm{d}}}\right)
\end{aligned}
$$

Here $M_{\mathrm{w}}, \sigma_{\mathrm{w}}$ and $\rho_{\mathrm{w}}$ are the molar mass, surface tension, and density of pure water. The diameter growth factor $G_{\mathrm{D}}$ is defined as the ratio between the volume equivalent diameters of the aqueous droplet and of the dry aerosol particle $\left(G_{\mathrm{D}}=\right.$ $\left.D / D_{\mathrm{d}}\right)$.

The hygroscopicity parameter $\kappa_{\mathrm{V}}$ relates the volume of the dry aerosol particle $\left(V_{\mathrm{d}}\right)$ to the volume of water $\left(V_{\mathrm{w}}\right)$ and the activity of water $\left(a_{\mathrm{w}}\right)$ in the aqueous droplet:

$\frac{1}{a_{\mathrm{w}}}=1+\kappa_{\mathrm{v}} \frac{V_{\mathrm{d}}}{V_{\mathrm{w}}}$
$a_{\mathrm{w}}=\left(\frac{\kappa_{\mathrm{v}}}{G_{\mathrm{D}}^{3}-1}+1\right)^{-1}$

Equations (2)-(4) are commonly used to determine effective hygroscopicity parameters from hygroscopic growth or $\mathrm{CCN}$ activation measurements using hygroscopicity tandem differential mobility analyzer (HTDMA) and CCN counter techniques (e.g.: Petters and Kreidenweis, 2007; Petters et al., 2009; Gunthe et al., 2009; Mikhailov et al., 2009; Carrico et al., 2010; Rose et al., 2010, 2011; Duplissy et al., 2011 and references therein). In the analysis of laboratory and field measurement data it is often assumed that measured mobility equivalent diameters $\left(D, D_{\mathrm{d}}\right)$ can be regarded as volume equivalent diameters, and that the volume change of mixing is negligible ("volume additivity assumption"). The limitations of these assumptions for HTDMA and CCN experiments have been outlined and discussed in earlier studies (e.g., Krämer et al., 2000; Gysel et al., 2002; Rose et al., 2008; Mikhailov et al., 2004, 2009; Wang et al., 2010; and references therein). For an individual solute $(i)$, the 
hygroscopicity parameter can be related to the molar mass $\left(M_{i}\right)$, density $\left(\rho_{i}\right)$, and the van't Hoff factor or effective dissociation number $\left(J_{i}\right)$ of the solute:

$\kappa_{\mathrm{v}, i}=J_{i} \frac{\rho_{i} / M_{i}}{\rho_{\mathrm{w}} / M_{\mathrm{w}}}$

Thus, $\kappa_{\mathrm{v}, i}$ can be regarded as an effective molar density of ions or molecules in the solute normalized by the molar density of water $\left(\rho_{\mathrm{w}} / M_{\mathrm{w}} \approx 55 \mathrm{~mol} \mathrm{~L}^{-1}\right)$ which has been designated as "effective Raoult parameter" or "dilute hygroscopicity" of the solute (Mikhailov et al., 2009; Sullivan et al., 2009).

In concentrated solutions, $\kappa_{\mathrm{v}, i}$ is usually concentrationdependent (Mikhailov et al., 2009), but under dilute conditions it approaches a substance-specific fixed value which we designate as the "dilute hygroscopicity", $\kappa_{\mathrm{v}, i}^{0}$. This parameter is easy to calculate from tabulated values of $J_{i}$ for dilute aqueous solutions (Eq. 5).

\subsection{Mass-based hygroscopicity parameter $\kappa_{\mathrm{m}}$}

In analogy to the volume-based hygroscopicity parameter (Eq. 3), we define a mass-based hygroscopicity parameter $\kappa_{\mathrm{m}}$ :

$\frac{1}{a_{\mathrm{w}}}=1+\kappa_{\mathrm{m}} \frac{m_{\mathrm{d}}}{m_{\mathrm{w}}}$,

where $m_{\mathrm{d}}$ is the mass of the dry particle material and $m_{\mathrm{w}}$ is the mass of water in the wet particle (aqueous droplet).

Under the assumption of volume additivity, Eq. (3) and Eq. (6) can be combined to

$\kappa_{\mathrm{m}}=\kappa_{\mathrm{v}} \frac{\rho_{\mathrm{w}}}{\rho_{\mathrm{d}}}$

where $\rho_{\mathrm{d}}$ is the density of the dry particle material. In this case, the knowledge of $\rho_{\mathrm{d}}$ enables conversion of $\kappa_{\mathrm{v}}$ into $\kappa_{\mathrm{m}}$ and vice versa. On the other hand, independent measurements of $\kappa_{\mathrm{v}}$ and $\kappa_{\mathrm{m}}$ enable the determination of $\rho_{\mathrm{d}}$.

The mass-based dilute hygroscopicity, $\kappa_{\mathrm{m}, i}^{0}$, follows from Eq. (5) and Eq. (7); it is the van't Hoff factor for a dilute solution $\left(J_{i}^{0}\right)$ scaled by the ratio of the molar masses of water and solute:

$\kappa_{\mathrm{m}, i}^{0}=J_{i}^{0} \frac{M_{\mathrm{w}}}{M_{i}}$

By defining the mass growth factor $G_{\mathrm{m}}$ as

$G_{\mathrm{m}}=\frac{m_{\mathrm{w}}+m_{\mathrm{d}}}{m_{\mathrm{d}}}$

and combining Eq. (9) and Eq. (6) we obtain

$a_{\mathrm{w}}=\left(\frac{\kappa_{\mathrm{m}}}{G_{\mathrm{m}}-1}+1\right)^{-1}$

The mass-based relation between water activity and particle hygroscopicity specified in Eq. (10) is equivalent to the volume based formulation in Eq. (4). Due to mass conservation, however, the practical applicability of Eq. (10) and the precision of related parameters determined in mass-based experiments is not affected by deviations from spherical geometry and volume additivity that usually limit the applicability and precision of volume-based parameters determined in mobility diameter-based HTDMA and CCN experiments (e.g., Krämer et al., 2000; Gysel et al., 2002, 2004; Rose et al., 2008; Mikhailov et al., 2004, 2009; Wang et al., 2010; and references therein).

The mass-based definition of the hygroscopicity parameter $\kappa_{\mathrm{m}}$ (Eq. 6) avoids a complication that occurs in the volumebased definition of $\kappa_{\mathrm{v}}$ (Eq. 3): the theoretical distinction and practical determination of specific volume vs. partial specific volume (alias molar vs. partial molar volume) of water and solute in a solution droplet. This distinction had not been addressed and specified in the original volume-based definition of $\kappa_{\mathrm{v}}$ (Petters and Kreidenweis, 2007), but it is relevant in systems where the volumes of mixed components are not linearly additive.

If the densities of the dry solute and of the solution are known, the masses of dry particles and aqueous droplets can be easily converted into volume equivalent diameters: $D_{\mathrm{d}}^{3}=6 m_{\mathrm{d}} /\left(\pi \rho_{\mathrm{d}}\right), D^{3}=6 G_{\mathrm{m}} m_{\mathrm{d}} /(\pi \rho)$, and $D=$ $D_{\mathrm{d}}\left(G_{\mathrm{m}} \rho_{\mathrm{d}} / \rho\right)^{1 / 3}$, where $\rho$ is the density of the aqueous solution droplet. For dilute aqueous solution droplets with $\rho \approx \rho_{\mathrm{w}}$ follows

$D=D_{\mathrm{d}}\left(G_{\mathrm{m}} \frac{\rho_{\mathrm{d}}}{\rho_{\mathrm{w}}}\right)^{1 / 3}$

By inserting Eq. (10) and Eq. (11) in Eq. (2), we obtain an approximate mass-based $\kappa_{\mathrm{m}}$-Köhler equation:

$$
\frac{\mathrm{RH}}{100 \%}=s_{\mathrm{w}} \approx\left(\frac{\kappa_{\mathrm{m}}}{G_{\mathrm{m}}-1}+1\right)^{-1} \exp \left(\frac{4 \sigma_{\mathrm{w}} M_{\mathrm{w}}}{R T \rho_{\mathrm{w}} D_{\mathrm{d}}}\left[\frac{\rho_{\mathrm{w}}}{\rho_{\mathrm{d}} G_{\mathrm{m}}}\right]^{1 / 3}\right)
$$

The critical mass growth factor $\left(G_{\mathrm{m}, \mathrm{c}}\right)$ and the critical water vapor saturation ratio $\left(s_{\mathrm{w}, \mathrm{c}}\right)$ for the $\mathrm{CCN}$ activation of an aerosol particle with dry diameter $D_{\mathrm{d}}$ and hygroscopicity $\kappa_{\mathrm{m}}$ correspond to the maximum value of $s_{\mathrm{w}}$ according to Eq. (12) $\left(\mathrm{d} s_{\mathrm{w}} / \mathrm{d} G_{\mathrm{m}}=0\right)$ :

$G_{\mathrm{m}, \mathrm{c}}=\left(\frac{3 \kappa_{\mathrm{m}} D_{\mathrm{d}}}{A}\right)^{3 / 2}\left(\frac{\rho_{\mathrm{d}}}{\rho_{\mathrm{w}}}\right)^{1 / 2}$

$s_{\mathrm{w}, \mathrm{c}}=\exp \left[\frac{2}{3}\left(\frac{A}{D_{\mathrm{d}}}\right)^{3 / 2}\left(\frac{\rho_{\mathrm{w}}}{3 \kappa_{\mathrm{m}} \rho_{\mathrm{d}}}\right)^{1 / 2}\right]$

with $A=\frac{4 \sigma_{\mathrm{w}} M_{\mathrm{w}}}{R T \rho_{\mathrm{w}}}$.

Exponential series expansion, cancellation of higher order terms, and rearrangement of Eq. (14) lead to the following approximate relation between the critical dry diameter of CCN activation $\left(D_{\mathrm{d}, \mathrm{c}}\right)$ and water vapor supersaturation $\left(S_{\mathrm{W}}=\left(s_{\mathrm{W}}-1\right) \cdot 100 \%\right)$ :

$D_{\mathrm{d}, \mathrm{c}}=A \cdot\left(\frac{4 \rho_{\mathrm{w}}}{27 \kappa_{\mathrm{m}} \rho_{\mathrm{d}}}\right)^{1 / 3}\left(\frac{S_{\mathrm{w}}}{100 \%}\right)^{-2 / 3}=\beta \cdot S_{\mathrm{w}}^{-2 / 3}$ 
with $\beta=A \cdot\left(\frac{4 \rho_{\mathrm{w}}}{27 \kappa_{\mathrm{m}} \rho_{\mathrm{d}}}\right)^{1 / 3}\left(\frac{1}{100 \%}\right)^{-2 / 3}$. A detailed derivation of Eq. (15) is given in Appendix A.

\subsection{Hygroscopicity parameter interaction model (KIM)}

In analogy to Petters and Kreidenweis (2008, Eq. 10), the mass-based hygroscopicity parameter of a multi-component particle can be approximated by a simple mixing rule that builds on the Zdanovskii-Stokes-Robinson (ZSR) approach (Stokes and Robinson, 1966; Seinfeld and Pandis, 2006):

$$
\begin{aligned}
& \kappa_{\mathrm{m}}=\sum_{i} f_{i} \kappa_{\mathrm{m}, i} H\left(y_{\mathrm{m}, i}\right) \\
& y_{\mathrm{m}, i}=\left(G_{\mathrm{m}}-1\right) C_{\mathrm{m}, i} / f_{i} \\
& H\left(y_{\mathrm{m}, i}\right)= \begin{cases}y_{\mathrm{m}, i} & \text { if } y_{\mathrm{m}, i}<1 \quad \text { (partly dissolved) } \\
1 & \text { if } y_{\mathrm{m}, i} \geq 1 \quad \text { (fully dissolved) }\end{cases}
\end{aligned}
$$

Here $f_{i}$ is the dry mass fraction of the solute component $i$, $C_{\mathrm{m}, i}$ is the solubility of the solute in water (mass of dissolved compound $i$ per unit mass of water under equilibrium conditions), and $H\left(y_{\mathrm{m}, i}\right)$ is the relative fraction of component $i$ that is actually dissolved in the aqueous phase. Accordingly, water insoluble components with $\kappa_{\mathrm{m}} \approx 0$ do not contribute to the overall particle hygroscopicity. For completely dissolved particles, all values of $y_{\mathrm{m}, i}$ equal unity, and $\kappa_{\mathrm{m}}$ is given by the simple relation

$\kappa_{\mathrm{m}}=\sum_{i} f_{i} \kappa_{\mathrm{m}, i}$

Note that in Eq. (16) and Eq. (17) the hygroscopicity parameters of individual chemical components $\kappa_{\mathrm{m}, i}$ are weighted by the corresponding mass fractions, $f_{i}$, which are usually easier to determine than the volume fractions. Due to the difficulties involved in obtaining correct density estimates for mixtures of organic and inorganic compounds in atmospheric aerosol particles, many recent studies applying a hygroscopicity parameter mixing rule used mass fractions as a proxy for volume fractions (e.g., Kreidenweis et al., 2008; Gunthe et al., 2009, 2011; Pringle et al., 2010; Rose et al., 2011).

In the highly dilute solution droplets usually formed at high RH and upon CCN activation, the hygroscopicity parameters of individual solute components $\left(\kappa_{\mathrm{m}, i}\right)$ approach the dilute hygroscopicity values $\kappa_{\mathrm{m}, i}^{0}$ that can be estimated using Eq. (8) and inserted in Eq. (16) or Eq. (17), respectively.

In the highly concentrated solutions formed at low RH, however, the hygroscopicity of aerosol particles does not always follow the simple ZSR approach (ideal mixing). Interactions between solute ions and molecules can lead to either higher or lower solubilities and hygroscopicity parameters as compared to single-component and dilute solutions (Marcolli et al., 2004; Marcolli and Krieger, 2006; Mikhailov et al., 2009).

To describe the non-ideal behavior of concentrated solutions, we propose a hygroscopicity parameter interaction model, briefly $\kappa_{\mathrm{m}}$-interaction model (KIM), that combines dilute hygroscopicity parameters with additional terms of cross- or self-interaction between molecular and ionic species:

$\kappa_{\mathrm{m}}=\sum_{i} K_{\mathrm{m}, i}$,

where the parameter $K_{\mathrm{m}, i}$ for each component is defined by

$$
K_{\mathrm{m}, i}=\left\{\begin{array}{c}
\left(\kappa_{\mathrm{m}, i}^{0}+\delta \kappa_{\mathrm{m}, i j}+\delta \kappa_{\mathrm{m}, i i}\right)\left(G_{\mathrm{m}}-1\right) C_{\mathrm{m}, i} \\
\text { if }\left(G_{\mathrm{m}}-1\right) C_{\mathrm{m}, i}<f_{i} \text { (partly dissolved) } \\
\left(\kappa_{\mathrm{m}, i}^{0}+\delta \kappa_{\mathrm{m}, i j}+\delta \kappa_{\mathrm{m}, i i}\right) f_{i} \\
\text { if }\left(G_{\mathrm{m}}-1\right) C_{\mathrm{m}, i} \geq f_{i} \text { (fully dissolved) }
\end{array}\right.
$$

Here $\delta \kappa_{\mathrm{m}, i j}$ and $\delta \kappa_{\mathrm{m}, i i}$ are defined as incremental hygroscopicity terms accounting for cross- and self-interactions of molecular and ionic species, respectively. Accounting of binary interactions between solutes in the aqueous solution droplet (Clegg et al., 2001, 2003), the concentration dependence of the incremental terms $\delta \kappa_{\mathrm{m}, i j}$ and $\delta \kappa_{\mathrm{m}, i i}$ can be described by:

$$
\begin{aligned}
& \delta \kappa_{\mathrm{m}, i j}=c_{\mathrm{m}, i} \sum_{i>j} \alpha_{i j} c_{\mathrm{m}, j} \\
& \delta \kappa_{\mathrm{m}, i i}=\alpha_{i i} c_{\mathrm{m}, i}^{2}
\end{aligned}
$$

Here $\alpha_{i j}$ and $\alpha_{i i}$ are cross- and self-interaction coefficients, respectively; $c_{\mathrm{m}, i}$ and $c_{\mathrm{m}, j}$ are the mass concentrations of individual components $(i, j)$ in the aqueous solution expressed here as mass of solute per unit mass of water. Depending on the nature of solute interaction, the interaction coefficients and the resulting incremental hygroscopicity terms can assume positive or negative values. Accordingly, the concentration dependence of $\kappa_{\mathrm{m}}$ can be expressed as follows:

$\kappa_{\mathrm{m}}=\sum_{i} \kappa_{\mathrm{m}, i}^{0} c_{\mathrm{m}, i}+\sum_{i} \sum_{j>i} \alpha_{i j} c_{\mathrm{m}, i} c_{\mathrm{m}, j}+\sum_{i} \alpha_{i i} c_{\mathrm{m}, i}^{2}$

In the double sum on the right hand side of Eq. (21), selfinteractions are excluded and each pair of solutes is counted only once $(j>i)$. The mass concentration of each component in the aqueous solution, $c_{\mathrm{m}, i}$, can be calculated either from the solubility $C_{\mathrm{m}, i}$ (if component $i$ is only partially dissolved) or from the dry mass fraction $f_{i}$ (if component $i$ is fully dissolved):

$c_{\mathrm{m}, i}= \begin{cases}C_{\mathrm{m}, i} & \text { if }\left(G_{\mathrm{m}}-1\right) C_{\mathrm{m}, i}<f_{i} \\ f_{i} /\left(G_{\mathrm{m}}-1\right) & \text { if }\left(G_{\mathrm{m}}-1\right) C_{\mathrm{m}, i} \geq f_{i}\end{cases}$

For a system consisting of fully dissolved (fd) and partly dissolved (pd) components, Eq. (18) to Eq. (22) can be combined into: 


$$
\begin{aligned}
& \kappa_{\mathrm{m}}= \\
& \sum_{i \in \mathrm{pd}}\left(\kappa_{\mathrm{m}, i}^{0}+C_{\mathrm{m}, i}\left[\sum_{j \in \mathrm{fd}} \alpha_{i j} \frac{f_{j}}{G_{\mathrm{m}}-1}+\sum_{\substack{j \in \mathrm{pd} \\
j>i}} \alpha_{i j} C_{\mathrm{m}, j}\right]+\alpha_{i i} C_{\mathrm{m}, i}^{2}\right) \\
& \left(G_{\mathrm{m}}-1\right) C_{\mathrm{m}, i}+ \\
& \sum_{i \in \mathrm{fd}}\left(\kappa_{\mathrm{m}, i}^{0}+\frac{f_{i}}{\left(G_{\mathrm{m}}-1\right)}\left[\sum_{\substack{j \in \mathrm{fd} d \\
j>i}} \alpha_{i j} \frac{f_{j}}{\left(G_{\mathrm{m}}-1\right)}+\sum_{j \in \mathrm{pd}} \alpha_{i j} C_{\mathrm{m}, j}\right]+\alpha_{i i} \frac{f_{i}^{2}}{\left(G_{\mathrm{m}}-1\right)^{2}}\right) f_{i}
\end{aligned}
$$

where

$i \in \mathrm{pd}$, if $\left(G_{\mathrm{m}}-1\right) C_{\mathrm{m}, i}<f_{i}$

$i \in \mathrm{fd}$, if $\left(G_{\mathrm{m}}-1\right) C_{\mathrm{m}, i} \geq f_{i}$.

Here the designation $i \in$ pd means that component $i$ is only partially dissolved in the aqueous phase, while the designation $i \in \mathrm{fd}$ refers to a component that is fully dissolved in the aqueous phase. For $i \in \mathrm{pd}$ the aqueous phase concentration $c_{\mathrm{m}, i}$ depends on $C_{\mathrm{m}, i}$, and for $i \in \mathrm{fd}$ the aqueous phase concentration $c_{\mathrm{m}, i}$ depends on $G_{\mathrm{m}}$ and $f_{i}$ as specified in Eq. (22).

In multi-component systems, the solubility of an individual component $C_{\mathrm{m}, i}$ in the mixture is not necessarily the same as the solubility of the component in pure water, $C_{\mathrm{m}, \mathrm{w}, i}$ (single-component system). Interactions between different substances can increase or decrease the solubility of individual components (Marcolli et al., 2004; Marcolli and Krieger, 2006). The influence of multiple solutes on the solubility of individual components can be described according to the Setschenov equation (Setschenov, 1889):

$C_{\mathrm{m}, i} / C_{\mathrm{m}, \mathrm{w}, i}=\exp \left[\sum_{j \in \mathrm{pd}} \eta_{i j} C_{\mathrm{m}, j}+\sum_{j \in \mathrm{fd}} \eta_{i j}\left(\frac{f_{j}}{G_{\mathrm{m}}-1}\right)\right]$,

where $\eta_{i j}$ is the salting out constant.

If all substances are just partly dissolved (pd) and exist also in a non-dissolved phase, the concentration of each component is given by the eutonic solubility, $C_{\mathrm{m}, i}^{\mathrm{eu}}$. In this case, Eq. (23) can be reduced to

$$
\begin{gathered}
\kappa_{\mathrm{m}}=\sum_{i \in \mathrm{pd}}\left(\kappa_{\mathrm{m}, i}^{0}+C_{\substack { \mathrm{m}, i \\
\begin{subarray}{c}{j \in \mathrm{pd}, j>i{ \mathrm { m } , i \\
\begin{subarray} { c } { j \in \mathrm { pd } , \\
j > i } }\end{subarray}}^{\mathrm{eu}} \alpha_{i j} C_{\mathrm{m}, j}^{\mathrm{eu}}+\alpha_{i i}\left(C_{\mathrm{m}, i}^{\mathrm{eu}}\right)^{2}\right) \\
\left(G_{\mathrm{m}}-1\right) C_{\mathrm{m}, i}^{\mathrm{eu}} .
\end{gathered}
$$

Combining Eq. (26) with Eq. (10) yields a constant water activity independent of $G_{\mathrm{m}}$, which is characteristic for stepwise phase transitions (deliquescence or efflorescence). The term eutonic solubility normally refers to a liquid phase in stable equilibrium with multiple crystalline phases. Partly dissolved solutes may also co-exist in meta-stable equilibrium with amorphous phases. For this "quasi-eutonic" state, the maximum aqueous phase concentration of a solute can be characterized by an apparent solubility, $C_{\mathrm{m}, i}^{\mathrm{ap}}$ replacing the eutonic solubility $C_{\mathrm{m}, i}^{\mathrm{eu}}$ in Eq. (26). Apparent solubilities are well-established parameters for the description of the water interactions of amorphous substances as discussed below and in the scientific literature dealing with semi-solid or solid amorphous organics in the pharmaceutical and food sciences (Mosharraf and Nyström, 1999; Hancock and Parks, 2000; Murdande et al., 2010, 2011). In contrast to the thermodynamically fixed value of equilibrium solubility, however, the apparent solubility of a substance is a kinetically limited parameter that may vary depending on the pre-treatment and history of the investigated system. The apparent solubility enhancement ratio $R_{\mathrm{ap}, i}=C_{\mathrm{m}, i}^{\mathrm{ap}} / C_{\mathrm{m}, i}$ can be used to describe the degree of supersaturation and amorphicity/metastability of the system (Hancock and Parks, 2000; Murdande et al., 2010, 2011).

If all substances are completely dissolved, Eq. (23) can be reduced to

$\kappa_{\mathrm{m}}=\sum_{i \in \mathrm{fd}}\left(\kappa_{\mathrm{m}, i}^{0}+\frac{f_{i}}{\left(G_{\mathrm{m}}-1\right)} \sum_{\substack{j \in \mathrm{fd}, j>i}} \alpha_{i j} \frac{f_{j}}{\left(G_{\mathrm{m}}-1\right)}+\alpha_{i i} \frac{f_{i}^{2}}{\left(G_{\mathrm{m}}-1\right)^{2}}\right) f_{i}$

In case of dilute solutions $\left(G_{\mathrm{m}} \gg 1\right)$, the relative importance of the incremental hygroscopicity terms decreases and Eq. (27) can be further reduced to Eq. (17).

For a single component system with $f_{i}=1, f_{j}=0$, and $\alpha_{i i}=\alpha$, Eq. (23) can be simplified to

$\kappa_{\mathrm{m}}=\left(\kappa_{\mathrm{m}}^{0}+\alpha C_{\mathrm{m}}^{2}\right)\left(G_{\mathrm{m}}-1\right) C_{\mathrm{m}}$

if $\left(G_{\mathrm{m}}-1\right) C_{\mathrm{m}}<1$ (partly dissolved)

$\kappa_{\mathrm{m}}=\kappa_{\mathrm{m}}^{0}+\frac{\alpha}{\left(G_{\mathrm{m}}-1\right)^{2}}$

if $\left(G_{\mathrm{m}}-1\right) C_{\mathrm{m}} \geq 1$ (fully dissolved)

Equation (29) can be combined with Eq. (8), Eq. (10), and with the relation

$c_{\mathrm{m}}=\left(G_{\mathrm{m}}-1\right)^{-1}=\mu M$

to obtain an explicit expression of water activity in the aqueous solution of a fully dissolved single solute with molar mass $M$, molality $\mu$ and van't Hoff factor $J^{0}$ :

$$
\begin{aligned}
a_{\mathrm{w}} & =\left(1+\kappa_{\mathrm{m}}^{0} c_{\mathrm{m}}+\alpha c_{\mathrm{m}}^{3}\right)^{-1}=\left(1+\frac{\kappa_{\mathrm{m}}^{0}}{\left(G_{\mathrm{m}}-1\right)}+\frac{\alpha}{\left(G_{\mathrm{m}}-1\right)^{3}}\right)^{-1} \\
& =\left(1+J^{0} \mu M_{\mathrm{w}}+\alpha(\mu M)^{3}\right)^{-1}
\end{aligned}
$$

This expression represents a middle way between the simplistic assumption of a constant single hygroscopicity parameter and the complex multi-parameter models typically using four or more semi-empirical parameters for a single solute system (e.g.: AIM, E-AIM, ADDEM, UNIFAC, AIOMFAC as specified in the introduction). Note that the 
Table 2. Atmospheric aerosol samples.

\begin{tabular}{llccc}
\hline Sample & $\begin{array}{l}\text { Sampling } \\
\text { location }\end{array}$ & $\begin{array}{c}\text { Sampling height } \\
\text { above ground }(\mathrm{m})\end{array}$ & $\begin{array}{l}\text { Sampling } \\
\text { period }\end{array}$ & $\begin{array}{c}\text { Aerosol mass used } \\
\text { for FDHA analysis (mg) }\end{array}$ \\
\hline AMAZE & $\begin{array}{l}\text { Manaus, Brazil } \\
02^{\circ} 35^{\prime} \mathrm{S}, 60^{\circ} 12^{\prime} \mathrm{W}\end{array}$ & 39 & $15-20$ Feb 2008 & $0.061 \pm 0.002$ \\
\hline SPB & $\begin{array}{l}\text { Saint-Petersburg, Russia } \\
59^{\circ} 88^{\prime} \mathrm{N}, 29^{\circ} 82^{\prime} \mathrm{E}\end{array}$ & 15 & $18-27$ May 2009 & $0.60 \pm 0.01$ \\
\hline
\end{tabular}

more detailed solute interaction models are generally also mass-based rather than volume-based for the reasons outlined above (mass conservation vs. volume non-additivity).

Inserting the equilibrium solubility $C_{\mathrm{m}}$ for the mass concentration $c_{\mathrm{m}}$ in Eq. (31) and combination with Eq. (12) leads to the following explicit analytical expression for the relative humidity threshold of the deliquescence of solid particles $\left(\mathrm{RH}_{\mathrm{d}}\right)$ :

$$
\begin{aligned}
& \mathrm{RH}_{\mathrm{d}} \approx 100 \times\left[\left(\kappa_{\mathrm{m}}^{0}+\alpha C_{\mathrm{m}}^{2}\right)+1\right]^{-1} \\
& \exp \left[\frac{4 \sigma_{\mathrm{w}} M_{\mathrm{w}}}{R T \rho_{\mathrm{w}} D_{\mathrm{d}}}\left(\frac{\rho_{\mathrm{w}}}{\rho_{\mathrm{d}}\left(C_{\mathrm{m}}^{-1}+1\right)}\right)^{1 / 3}\right]
\end{aligned}
$$

The same equation yields the relative humidity threshold of the efflorescence of supersaturated solution droplets $\left(\mathrm{RH}_{\mathrm{e}}\right)$ when the apparent solubility $C_{\mathrm{m}, i}^{\mathrm{ap}}$ as defined and used below is inserted (Sect. 4.1).

General relations between the KIM approach, the osmotic coefficient of multi-component aqueous solutions, and the extended ZSR model approach of Clegg et al. (2003) are specified and discussed in Appendix B.

\section{Experiments}

\subsection{Aerosol sampling and composition}

Atmospheric aerosol samples in the submicrometer size range were collected at a pristine tropical rainforest site and at a suburban boreal forest site as specified in Table 2. The tropical sample was collected during the Amazonian Aerosol Characterization Experiment in February 2008 (AMAZE-08, Martin et al., 2010) at the rainforest research station TT34 near Manaus, Brazil. Concurrent chemical and microscopic analyses indicate that the AMAZE sample consisted mostly of biogenic secondary organic aerosol (SOA) accounting for up to $85 \%$ of the submicrometer particle mass (Chen et al., 2009; Gunthe et al., 2009; Martin et al., 2010; Pöschl et al., 2010).

The boreal sample was collected at the Institute of Physics of the State University of Saint-Petersburg in suburban forest environment of Petrodvoretz near the city of SaintPetersburg, Russia, in May 2009 (SPB sample). Detailed chemical composition data are not available for the SPB sample, but a thermal combustion method (Kuhlbusch et al., 1998) supplemented by aqueous extraction experiments (Mayol-Bracero et al., 2002) indicate that the total watersoluble fraction of the collected particulate matter was only $30 \%$ and the water-soluble organic fraction was as low as $10 \%$. These values are consistent with the FDHA measurement results presented below: low hygroscopicity and relatively low importance of molecular interactions in the SPB sample.

The particles were collected by passing an air flow of $20 \mathrm{~L} \mathrm{~min}^{-1}$ through a cyclone with $1 \mu \mathrm{m}$ cut-off diameter (URG-2000-30EHB), a silica gel diffusion drier, and a $47 \mathrm{~mm}$ Teflon-coated glass fiber filter (Pallflex T60A20, Pall, Germany).

Reference aerosol samples of sodium chloride $(\mathrm{NaCl}$, $>99.5 \%$, Merck) and ammonium sulfate $\left(\left(\mathrm{NH}_{4}\right)_{2} \mathrm{SO}_{4}\right.$ or AS, Fluka, $>99.5 \%$ ) were generated by nebulization of aqueous solutions with a salt mass fraction $0.1 \%$ in deionized water (18.2 $\mathrm{M} \Omega \mathrm{cm}$, Milli Q plus 185, Millipore). The sampling system and procedures were the same as applied for the atmospheric aerosol samples, except for the particle size selection using a Battelle-type pre-impactor (model I-1, PIXE International Corporation, Florida, USA) (Mitchel and Pilcher, 1959) with $1 \mu \mathrm{m}$ cut-off diameter at a flow rate of $1 \mathrm{Lmin}^{-1}$.

The size distributions of the investigated aerosols were measured with a mobility particle sizer. The mean diameters (and geometric standard deviations) of the number size distributions were: $139 \mathrm{~nm}$ (2.38) for AMAZE; $109.7 \mathrm{~nm}$ (1.77) for SPB; $81.6 \mathrm{~nm}$ (1.71) for AS; and $59.4 \mathrm{~nm}$ (1.47) for $\mathrm{NaCl}$.

\subsection{Water uptake measurements}

Mass-based water uptake measurements were performed with a filter-based differential hygroscopicity analyzer (FDHA) using the atmospheric aerosol filter samples and reference samples collected as described above. Circular aliquots of $13 \mathrm{~mm}$ diameter were cut from the aerosol loaded filters and mounted in the FDHA system shown in Fig. 1. The filter loadings of the atmospheric samples are listed in Table 2, the loadings of the $\mathrm{NaCl}$ and $\mathrm{AS}$ reference samples were $0.132 \mathrm{mg}$ and $0.130 \mathrm{mg}$, respectively. Details of the experimental setup and calibration are described elsewhere 


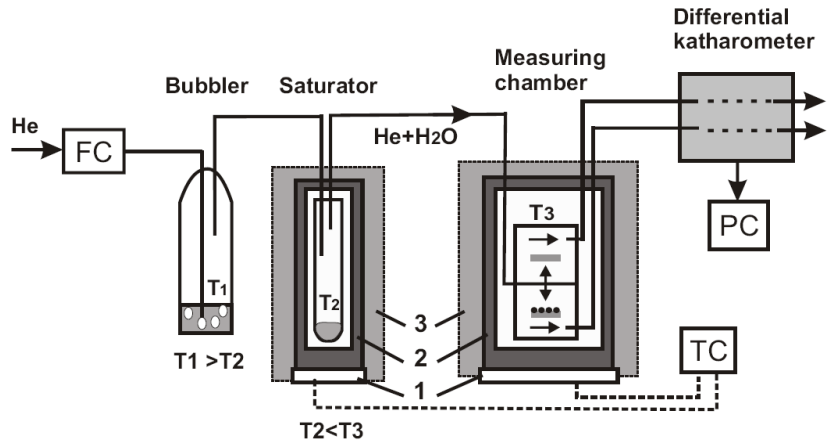

Fig. 1. Schematic set-up of the filter-based differential hygroscopicity analyzer (FDHA): FC - flow controller, TC - temperature controller, PC - computer. T1, T2, and T3 - temperature sensors. 1 Peltier elements, 2 - copper housing (double wall cylinder), 3 - insulation.

(Mikhailov et al., 2011); the operating principles are only briefly outlined here.

In the FDHA system, the carrier gas (helium) was humidified with a bubbler (T1), equilibrated in a saturator $(\mathrm{T} 2<\mathrm{T} 1)$, and then passed through a pair of differential measurement cells $(\mathrm{T} 3>\mathrm{T} 2)$. The reference cell contains a clean filter aliquot; the other cell contains the aerosol loaded filter aliquot. The mass of water taken up by the aerosol particles on the loaded filter aliquot was determined by a differential katharometer and recorded by an analog-digital converter and a personal computer. The measurement uncertainties depend on the weighing accuracy of dry particle mass (aerosol loading), absorbed water mass (aerosol hygroscopicity), and water vapor measurement precision of the katharometer (Mikhailov et al., 2011). The experimental conditions in the measurements cells were close to ambient temperature and pressure $(\sim 295 \mathrm{~K}, \sim 1 \mathrm{~atm})$.

In this study, the largest uncertainties in the determination of mass growth factors, $G_{\mathrm{m}}$ (Eq. 9) were associated with the AMAZE sample: $\sim 1 \%$ at $30 \% \mathrm{RH}$ and $\sim 8 \%$ at $99 \% \mathrm{RH}$. The relative humidity of the FDHA water uptake measurement is determined from the temperature ratio between the water vapor saturator (T2) and the measurement cells (T3) using empirical formulas recommended by the World Meteorological Organisation (Flatau et al., 1992). The accuracy at $99 \% \mathrm{RH}$ was $\pm 0.06 \% \mathrm{RH}$, resulting from accurate temperature control using a double-wall copper housing with forced thermal insulation and precise temperature measurements ( $\pm 0.01 \mathrm{~K}, 42095$-Pt100; KELVIMAT 4306, Burster). The water uptake experiments were performed in two modes: hydration $=$ increasing $\mathrm{RH}$; dehydration $=$ decreasing RH. Hydration/dehydration mass growth factor measurements took on average 10-60 min at 10-70\% RH, while above $98 \% \mathrm{RH}$ it took 1-2 days to reach thermodynamic equilibrium.

To avoid or minimize potential particle coagulation in the course of humidification and drying cycles we used relatively low filter loadings $\left(\sim 0.1 \mathrm{mg} \mathrm{cm}^{-2}\right)$. SEM analyses showed that under these conditions the average distance between particles was larger than the expected diameter growth factors $\left(G_{\mathrm{D}}=2-10\right.$ for $\mathrm{NaCl}$ at $\left.\mathrm{RH}=80-99 \%\right)$ (Mikhailov et al., 2011). Moreover, the hydration and dehydration experiments were performed in multiple cycles that went up to different maximum RH values $(60 \%, 80 \%, 99 \%)$ and yielded consistent results, indicating that coagulation at high RH had no significant effect.

The potential particle mass lost due to evaporation was monitored by weighing the loaded filters before and after water uptake measurements. These measurements as well as subsequent hygroscopic data obtained at repetitive dryinghumidifying cycles showed that the effect of particle evaporation was negligibly small for the atmospheric samples as well as the $\mathrm{NaCl}$ and $\mathrm{AS}$ reference samples.

\section{Measurement results and discussion}

\subsection{Sodium chloride and ammonium sulfate}

Figure $2 \mathrm{a}$ and $\mathrm{b}$ show the measured mass growth factors plotted against relative humidity $(\mathrm{RH})$ for the sodium chloride $(\mathrm{NaCl})$ and ammonium sulfate (AS) reference samples investigated in FDHA experiments. Upon hydration (increasing $\mathrm{RH}$ ), the inorganic salt crystals exhibited stepwise deliquescence transitions at $\mathrm{RH}_{\mathrm{d}}$ values of $75.8 \pm 0.2 \%$ for $\mathrm{NaCl}$ and $80.6 \pm 0.3 \%$ for AS. The Kelvin effect correction, which is needed for polydisperse aerosol samples (cf. Appendix C), gives $75.0 \%$ for $\mathrm{NaCl}$ and $79.9 \%$ for AS. These values are in a good agreement with literature data $\left(\mathrm{RH}_{\mathrm{d}, \mathrm{NaCl}}=\right.$ $75.3 \pm 0.1 \%, \mathrm{RH}_{\mathrm{d}, \mathrm{AS}}=79.9 \pm 0.5 \%$; Tang and Munkelwitz, 1993). From the mass growth factors measured after full deliquescence, i.e., at $76 \% \mathrm{RH}$ for $\mathrm{NaCl}$ and at $81 \% \mathrm{RH}$ for AS, we calculated the corresponding water solubilities using the relation $C_{\mathrm{m}}=1 /\left(G_{\mathrm{m}}-1\right)$ (Eq. 30$)$. The obtained values of $0.36 \pm 0.02 \mathrm{~g} \mathrm{~g}^{-1}$ for $\mathrm{NaCl}$ and $0.76 \pm 0.02 \mathrm{~g} \mathrm{~g}^{-1}$ for AS are in a good agreement with literature data on the equilibrium solubility of these salts in water at room temperature (Stephen and Stephen, 1963; Clarke and Glew, 1985; Tang and Munkelwitz, 1994; Marcolli et al., 2004). Upon dehydration (decreasing $\mathrm{RH}$ ), efflorescence of the solution droplets occurred at $\mathrm{RH}_{\mathrm{e}}$ values of $54 \pm 2 \%$ for $\mathrm{NaCl}$ and $41 \pm 1 \%$ for AS. The observed efflorescence thresholds are at the upper end of literature data reported for particles larger than $100 \mathrm{~nm}$ (35-40\% for AS, Ciobanu et al., 2010; 43-50\% for $\mathrm{NaCl}$, Gao et al., 2007), which may be due to partial coagulation and impurities inducing crystallization (Martin, 2000). The dashed model lines in Figs. $2 \mathrm{a}$ and $2 \mathrm{~b}$ were calculated using Eq. (30) with data of the Aerosol Inorganic Model (AIM, Clegg et al., 1998), which can be regarded as an accurate reference (Rose et al., 2008; Mikhailov et al., 2009). In these and subsequent model calculations relating water activity and relative humidity, we used Eq. (12) assuming $D_{\mathrm{d}}=D_{\text {eff }}$ as explained in Appendix C (Eq. C4). 

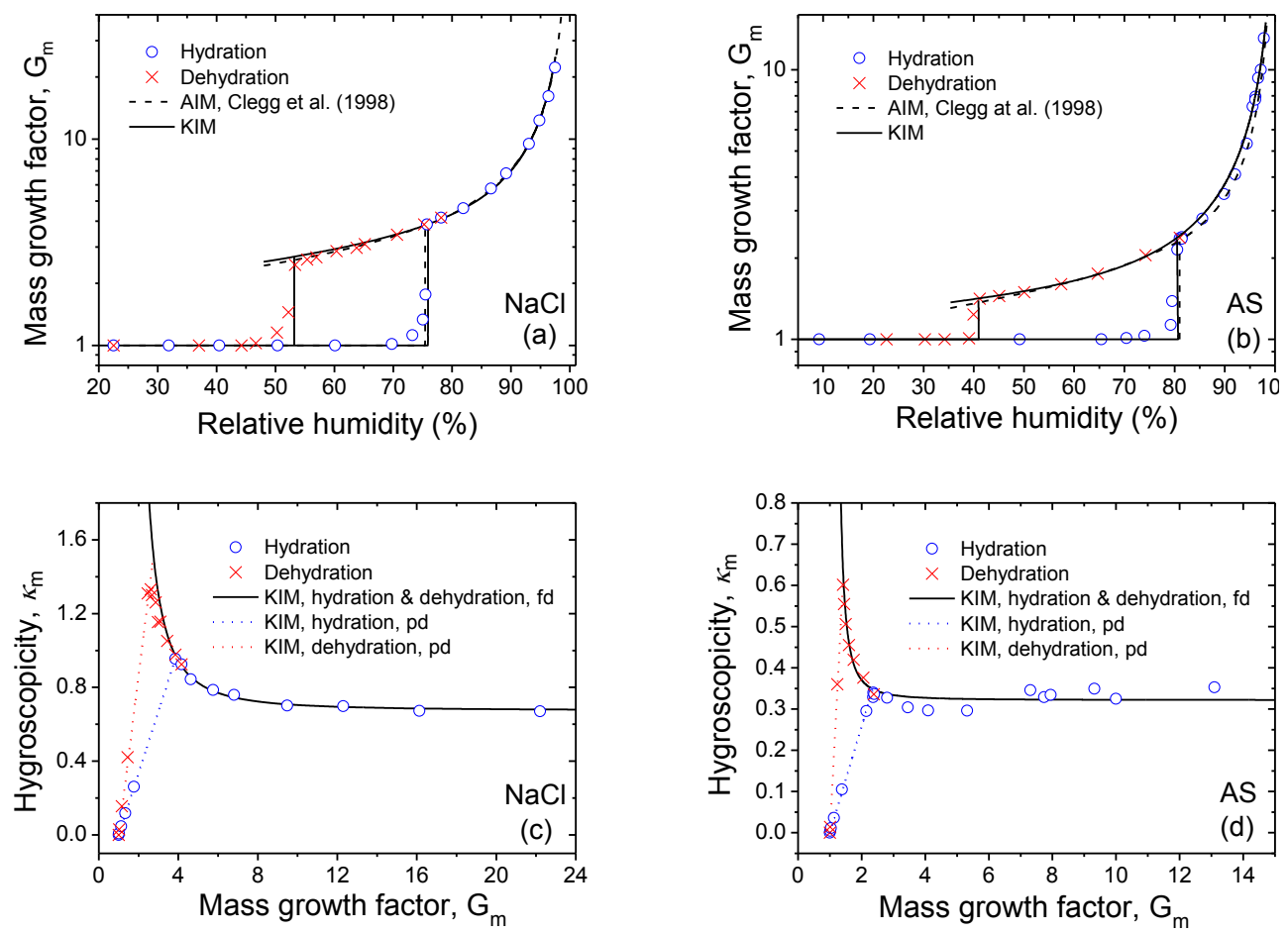

Fig. 2. Hygroscopic properties of sodium chloride $(\mathrm{NaCl})$ and ammonium sulfate $(\mathrm{AS})$ particles: $(\mathbf{a}, \mathbf{b})$ mass growth factors $\left(G_{\mathrm{m}}\right)$ observed as a function of relative humidity; (c, d) mass-based hygroscopicity parameters $\left(\kappa_{\mathrm{m}}\right)$ calculated as a function of mass growth factor (Appendix C, Eq. C2). The data points are from FDHA experiments of hydration (blue circles) and dehydration (red crosses). The lines represent different models: (a, b) KIM - black solid; AIM reference - black dashed; (c, d) KIM for fully dissolved (fd) particles (Eq.29) - black solid; KIM for partly dissolved (pd) particles (Eq. 28) - blue dotted upon hydration and red dotted upon dehydration.

Table 3. KIM fit parameters for inorganic reference salt and pure organic substance particle samples. $\kappa_{\mathrm{m}}^{0}$ and $\alpha$ are the dilute hygroscopicity and self-interaction parameters obtained with KIM model Eqs. (29) and (31); $n$ and $R^{2}$ are the number of data points and the coefficient of determination of the fit. $C_{\mathrm{m}}$ is the equilibrium water solubility determined upon deliquescence, and $C_{\mathrm{m}}^{\text {ap }}$ is the apparent solubility determined upon efflorescence.

\begin{tabular}{|c|c|c|c|c|c|c|c|c|c|}
\hline Sample & Data* & Data source & $\kappa_{\mathrm{m}}^{0}$ & $\alpha$ & $n$ & $R^{2}$ & $\begin{array}{l}\text { Fit } \\
\text { equation }\end{array}$ & $\begin{array}{l}C_{\mathrm{m}} \\
\left(\mathrm{g} \mathrm{g}^{-1}\right)\end{array}$ & $\begin{array}{l}C_{\mathrm{m}}^{\mathrm{ap}} \\
\left(\mathrm{g} \mathrm{g}^{-1}\right)\end{array}$ \\
\hline $\mathrm{NaCl}$ & FDHA & This study & $0.68 \pm 0.01$ & $2.35 \pm 0.07$ & 19 & 0.99 & 29 & $0.36 \pm 0.02$ & $0.58 \pm 0.01$ \\
\hline$\left(\mathrm{NH}_{4}\right)_{2} \mathrm{SO}_{4}(\mathrm{AS})$ & FDHA & This study & $0.32 \pm 0.01$ & $0.047 \pm 0.002$ & 18 & 0.96 & 29 & $0.76 \pm 0.02$ & $2.44 \pm 0.01$ \\
\hline Malonic acid (MA) & Raman & Yeung and Chan (2010) & $0.23 \pm 0.01$ & $1.49 \times 10^{-3} \pm 3.5 \times 10^{-4}$ & 19 & 0.56 & 29 & $1.58 \pm 0.03$ & $13.35 \pm 0.01$ \\
\hline \multirow[t]{2}{*}{ Levoglucosan (LG) } & $\mathrm{EDB}+$ bulk & Peng et al. (2001) & $0.22 \pm 0.01$ & $-1.62 \times 10^{-5} \pm 1.8 \times 10^{-6}$ & 36 & 0.97 & 31 & - & - \\
\hline & $\mathrm{EDB}+$ bulk & Chan et al. (2005) & $0.11 \pm 0.01$ & $-5.45 \times 10^{-6} \pm 4.0 \times 10^{-7}$ & 36 & 0.98 & 31 & - & - \\
\hline
\end{tabular}

* FDHA: filter-based differential hygroscopicity analyzer; EDB: electrodynamic balance, Raman: Raman micro-spectroscopy.

Figure $2 \mathrm{c}$ and $\mathrm{d}$ show the mass-based hygroscopicity parameters $\left(\kappa_{\mathrm{m}}\right)$ plotted against the mass growth factors measured for $\mathrm{NaCl}$ and $\mathrm{AS}$. The $\kappa_{\mathrm{m}}$ values were calculated as specified in Appendix C. We used the KIM model Eq. (29) for single solute systems to fit the data points for fully deliquesced $\mathrm{NaCl}$ and $\mathrm{AS}$ (solid black lines), and the obtained best fit parameter values and standard errors of the massbased dilute hygroscopicity parameter $\kappa_{\mathrm{m}}^{0}$ and of the solute interaction parameter $\alpha$ are listed in Table 3. For $\mathrm{NaCl}$, the best fit value of $\kappa_{\mathrm{m}}^{0}=0.67$ corresponds to a dilute van't Hoff factor $J^{0}=2.17$ (Eq. 8) and to a volume-based dilute hygroscopicity parameter $\kappa_{\mathrm{v}}^{0}=1.45$ (Eq. 7 with $\rho_{\mathrm{d}}=$ $\left.2.165 \mathrm{~g} \mathrm{~cm}^{-3}\right)$. For AS, $\kappa_{\mathrm{m}}^{0}=0.32$ corresponds to $J^{0}=2.35$ and to $\kappa_{\mathrm{v}}^{0}=0.57$ (Eq. 7 with $\rho_{\mathrm{d}}=1.769 \mathrm{~g} \mathrm{~cm}^{-3}$ ), which is consistent with Petters and Kreidenweis (2007) and calculations based on a $\mathrm{CCN}$ experiment and the Aerosol Inorganic model (AIM) (Rose et al., 2008).

By inserting $\kappa_{\mathrm{m}}^{0}$ and $\alpha$ from Table 3 in Eqs. (29) and (12), we obtained the KIM model results displayed in Fig. 2a and $\mathrm{b}$ (solid line). For both $\mathrm{NaCl}$ and $\mathrm{AS}$, the KIM two parameter model is in good agreement with the measurement data as well as with the much more complex AIM multi-parameter model (dashed line). 
The data points on the dry salt particle baseline in Fig. 2a and $\mathrm{b}$ correspond to the data points in the lower left corner of Fig. $2 \mathrm{c}$ and $\mathrm{d}\left(G_{\mathrm{m}}=1\right.$ and $\left.\kappa_{\mathrm{m}}=0\right)$. The data points in between the dry salt baseline and the hygroscopic growth curve for fully deliquesced particles indicate the co-existence of solid salt crystals with aqueous solution droplets, which can be explained by inhomogeneities in the salt particle samples (size, morphology, impurities, etc.) or non-uniform conditions in the experimental setup (spatial and temporal fluctuations in relative humidity; Biskos et al., 2006; Mikhailov et al., 2009). The KIM model Eq. (28) can be used to describe such partially deliquesced systems. With the parameters derived from the fit of Eq. (29) to the data for fully deliquesced salt samples $\left(\kappa_{\mathrm{m}}^{0}, \alpha\right.$, and $C_{\mathrm{m}}$ as specified in Table 3$)$, Eq. (28) yields the dotted blue model lines in Fig. $2 \mathrm{c}$ and $d$ that are in good agreement with the water uptake observed during partial deliquescence upon hydration. For the data points reflecting partial efflorescence upon dehydration, we applied Eq. (28) with $C_{\mathrm{m}}$ as a free fit parameter representing the apparent solubility of the salts in the supersaturated aqueous solution droplets. The apparent solubilities corresponding to the dotted red fit lines in Fig. $2 \mathrm{c}$ and $\mathrm{d}$ are $0.58 \pm 0.01 \mathrm{~g} \mathrm{~g}^{-1}$ for $\mathrm{NaCl}$ and $2.44 \pm 0.01 \mathrm{~g} \mathrm{~g}^{-1}$ for AS (Table 3). These values represent the maximum salt concentration in metastable, supersaturated aqueous solution droplets at $\mathrm{RH}<\mathrm{RH}_{\mathrm{d}}$.

\subsection{Levoglucosan}

Figure 3a shows mass growth factors of levoglucosan (LG) plotted against relative humidity. The data are from Chan et al. (2005) who used electrodynamic balance (EDB) and bulk measurement techniques and observed no stepwise deliquescence or efflorescence transitions, indicating that the samples were amorphous (Mikhailov et al., 2009). Throughout the investigated RH range of $3 \%$ to $98 \%$, the observed hygroscopic growth of the amorphous organic particles is well described by a fit of the KIM model Eq. (31) for deliquesced particles, and the corresponding hygroscopicity and interaction parameters $\kappa_{\mathrm{m}}^{0}$ and $\alpha$ for LG are given in Table 3 . The best fit value of $\kappa_{\mathrm{m}}^{0}=0.11$ corresponds to a dilute van't Hoff factor close to unity as expected for non-dissociating molecules $\left(J^{0}=0.99\right.$, Eq. 8) and to a volume-based dilute hygroscopicity parameter $\kappa_{\mathrm{v}}^{0}=0.18$ (Eq. 7, with $\rho_{\mathrm{d}}=$ $1.6 \mathrm{~g} \mathrm{~cm}^{-3}$ ). The KIM two-parameter equation fits the experimental data well as the empirical three-parameter approach used in earlier studies (Mikhailov et al., 2009) and much better than the more complex UNIFAC model with group interaction parameters taken from Hansen et al. (1991), which does not capture the shape of the measured growth curve (Fig. 3a). The near-unity van't Hoff factor and the small interaction parameter reflect near-ideal solution behavior of levoglucosan in agreement with the HTDMA measurement and model results of Mikhailov et al. (2009).

\subsection{Malonic acid}

Figure $3 \mathrm{~b}$ shows the hygroscopic growth of amorphous malonic acid (MA) observed by Peng et al. (2001) using electrodynamic balance (EDB) and bulk measurement techniques. The measurement data are well described by a fit of the KIM model Eq. (31), and the corresponding fit parameter values of $\kappa_{\mathrm{m}}^{0}$ and $\alpha$ are given in Table 3 . The best fit value of $\kappa_{\mathrm{m}}^{0}=0.22$ corresponds to a dilute van't Hoff factor $J^{0}=$ 1.33 (Eq. 8) and to a volume-based dilute hygroscopicity parameter $\kappa_{\mathrm{v}}^{0}=0.36$ (Eq. 7, with $\left.\rho_{\mathrm{d}}=1.619 \mathrm{~g} \mathrm{~cm}^{-3}\right)$. The results of the KIM two-parameter equation are nearly identical to the E-AIM results that are also displayed in Fig. $3 \mathrm{~b}$ and are based on a more complex approach with four fit parameters (Redlich-Kister expansion; McGlashan, 1963; Clegg and Seinfeld, 2006).

Figure 4a shows the hygroscopic growth of crystalline MA observed by Yeung and Chan (2010) who used Raman micro-spectroscopy and reported water-to-solute mass ratios (WSR) that are equivalent to mass growth factors $\left(G_{\mathrm{m}}=\mathrm{WSR}+1\right)$. The crystalline MA sample exhibited a stepwise deliquescence transition at $67 \% \mathrm{RH}$ (equilibrium solubility $C_{\mathrm{m}}=1.58 \mathrm{~g} \mathrm{~g}^{-1}$ ), and sharp changes in the position and width of the Raman signals indicated an efflorescence transition at $14 \% \mathrm{RH}$. The dependence of $\kappa_{\mathrm{m}}$ on $G_{\mathrm{m}}$ observed for crystalline MA (Fig. 4b) is qualitatively similar to the behavior observed for crystalline $\mathrm{NaCl}$ and AS (Fig. 2a, b). KIM model Eq. (29) was used to fit the data points for fully deliquesced MA (Fig. 4b, solid black line), and the corresponding fit parameters are given in Table 3. The goodness of fit for the Raman data is lower than for the EDB data, but nevertheless, the fit parameters and the corresponding model lines in Fig. $4 \mathrm{a}$ are in good agreement with each other and with the measurement data. With the equilibrium solubility determined upon hydration, $C_{\mathrm{m}}=1.58 \pm 0.03 \mathrm{~g} \mathrm{~g}^{-1}$, the KIM model Eq. (28) for partially deliquesced systems yields the dotted blue model line in Fig. 4b. A fit of the same equation to the data observed upon dehydration (red dotted line) yields an apparent solubility of $C_{\mathrm{m}}^{\mathrm{ap}}=13.35 \pm 0.01 \mathrm{~g} \mathrm{~g}^{-1}$.

The good agreement with measurement data for $\mathrm{NaCl}$, AS, LG and malonic acid shows that the KIM model approach is well suited to describe the hygroscopic growth and stepwise deliquescence/efflorescence transitions of crystalline inorganic and organic substances as well as the gradual deliquescence/efflorescence of amorphous organic substances. The KIM model results are also in good agreement with established reference models (AIM, E-AIM), but the latter usually depend on more parameters and KIM is easier to use for efficient fitting and description of new measurement data. Eqs. (29) and (31) with the dilute hygroscopicity parameter $\kappa_{\mathrm{m}}^{0}$ and the interaction parameter $\alpha$ enable efficient description of the RH and solute concentration dependence of the hygroscopicity of fully deliquesced single-component systems. Equation (28) enables the description of partially 

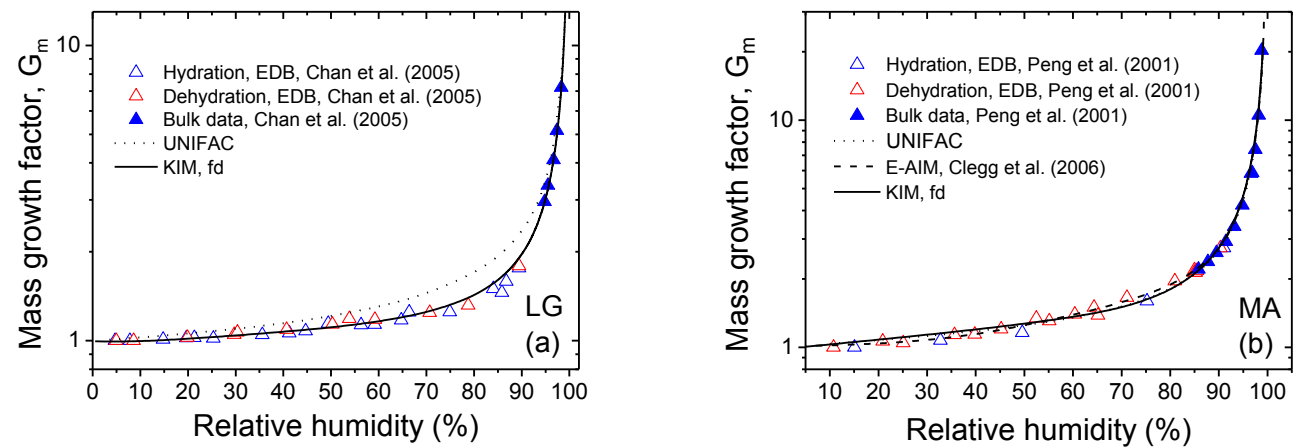

Fig. 3. Mass growth factors observed for amorphous levoglucosan (LG) and malonic acid (MA) particles as a function of relative humidity. Data points: bulk experiments (filled triangles) and EDB experiments (open triangles) of hydration (blue) and dehydration (red) from (a) Chan et al. (2005) and (b) Peng et al. (2001). Model lines: KIM for fully dissolved (fd) particles (Eq. 31) - black solid; UNIFAC - black dotted; E-AIM, Clegg et al. (2006) - black dashed.
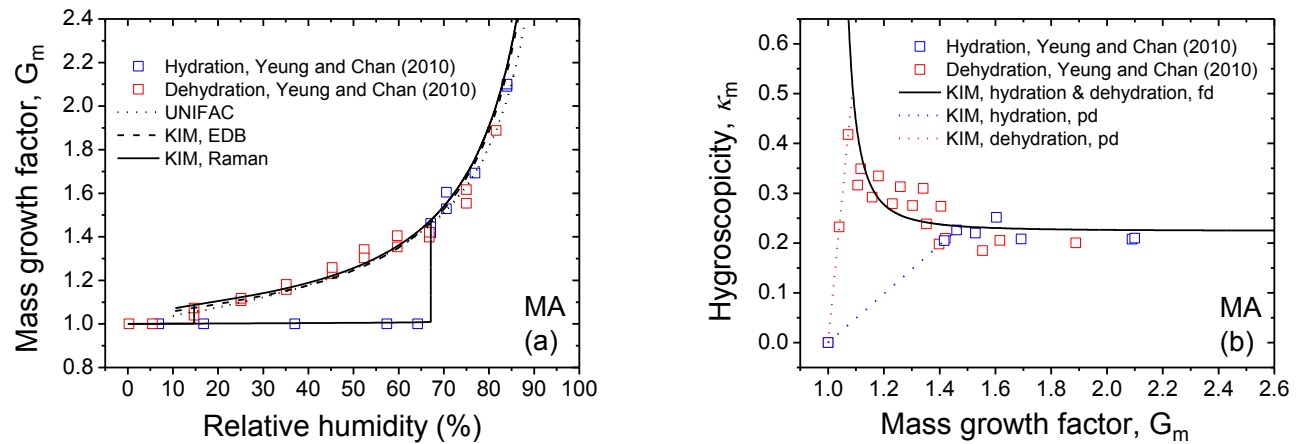

Fig. 4. Hygroscopic properties of crystalline malonic acid (MA) particles: (a) mass growth factors $\left(G_{\mathrm{m}}\right)$ observed as a function of relative humidity; (b) mass-based hygroscopicity parameters $\left(\kappa_{\mathrm{m}}\right)$ calculated as a function of mass growth factor (Eq. 10). Data points: micro-Raman experiments of hydration (blue) and dehydration (red) from Yeung and Chan (2010). Model lines: (a) UNIFAC with interaction parameters from Peng et al. (2001) - black dotted; KIM fit to micro-Raman data - black solid; KIM with fit parameters from EDB data for amorphous MA (Fig. 3b) - black dashed; (b) KIM for fully dissolved (fd) particles (Eq. 29) - black solid; KIM for partly dissolved (pd) particles (Eq. 28) - blue dotted upon deliquescence and red dotted upon efflorescence.

deliquesced systems, and Eq. (32) with the equilibrium solubility $C_{\mathrm{m}}$, or the apparent solubility $C_{\mathrm{m}, i}^{\mathrm{ap}}$ describes the $\mathrm{RH}$ threshold of deliquescence and efflorescence, respectively.

\subsection{Mixed malonic acid and ammonium sulfate}

Figure 5 shows the hygroscopic behavior of particles consisting of mixed malonic acid and ammonium sulfate (MAAS) with a mole ratio of $1: 1\left(f_{\mathrm{MA}}=0.441 ; f_{\mathrm{AS}}=0.559\right)$. The measurement data are from EDB experiments of Ling and Chan (2008) (stars), scanning EDB (SEDB) experiments of Choi and Chan (2002) (open triangles), and Raman micro-spectroscopic experiments by Yeung and Chan (2010) (open squares). Upon hydration (Fig. 5a), the mixed MAAS particles exhibit gradual deliquescence as expected for mixed crystalline or amorphous substances (Martin, 2000; Mikhailov et al., 2009). The onset of deliquescence occurred at much lower relative humidity $(\sim 30 \%)$ than predicted by the E-AIM (eutonic point at $\sim 63 \% \mathrm{RH}$, Clegg et al., 2006) and reported from earlier bulk measurements $(\sim 71 \%$,
Brooks et al., 2002), indicating an amorphous state of MA as discussed below. The observed hygroscopic growth of fully deliquesced particles ( $\mathrm{RH}>75 \%$ ) is in good agreement with predictions based on the E-AIM (Clegg and Seinfeld, 2006) and on the E-ZSR model (Clegg et al., 2004).

Upon dehydration (Fig. 5b), efflorescence was observed around $\sim 20 \% \mathrm{RH}$. In one of the particles investigated by Choi and Chan (2002), partial crystallization was observed at higher RH, but the experiment was likely influenced by contaminants (Yeung and Chan, 2010) and the data are not included in our study.

Figure $5 \mathrm{c}$ shows the mass-based hygroscopicity parameters plotted against the mass growth factors observed for the mixed MA-AS particles. The $\kappa_{\mathrm{m}}$ values were calculated by inserting the data pairs of $G_{\mathrm{m}}$ and $a_{\mathrm{w}}=\mathrm{RH} / 100 \%$ in Eq. (10). The observed dependence of $\kappa_{\mathrm{m}}$ on $G_{\mathrm{m}}$ exhibits three different sections labeled (Ia, Ib, II, and III). These sections can be classified as different regimes of hygroscopicity and described by KIM model equations as follows: 

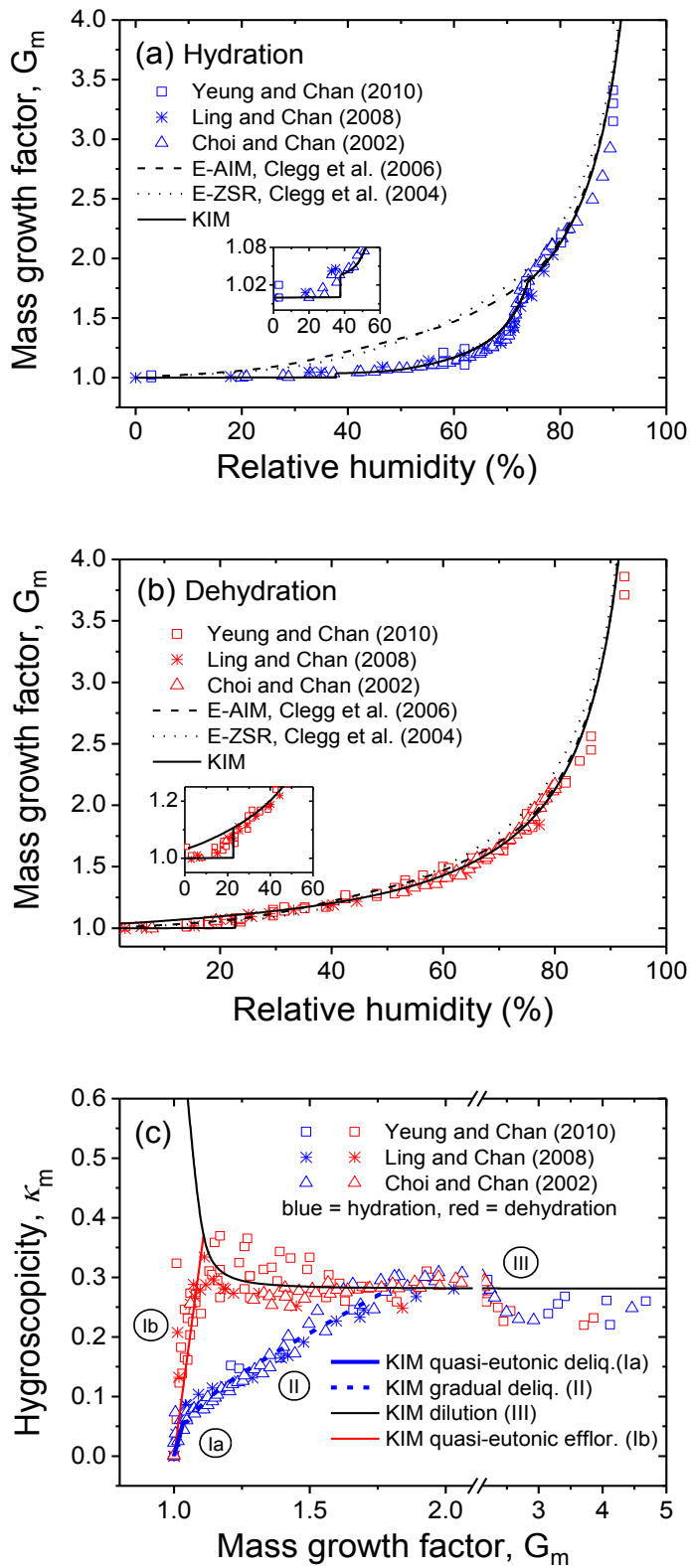

Fig. 5. Hygroscopic properties of mixed malonic acid - ammonium sulfate particles (MA-AS, mole ratio $1: 1)$ : $(\mathbf{a}, \mathbf{b})$ mass growth factors $\left(G_{\mathrm{m}}\right)$ observed as a function of relative humidity upon hydration (blue) and dehydration (red). (c) Mass-based hygroscopicity parameters $\left(\kappa_{\mathrm{m}}\right)$ calculated as a function of mass growth factor (Eq. 10). Labels Ia, Ib, II, and III indicate different regimes of hygroscopicity. Data points: EDB experiments (stars) from Ling and Chan (2008), SEDB experiments (triangles) from Choi and Chan (2002), and micro-Raman experiments (squares) from Yeung and Chan (2010). Model lines: (a, b) KIM - black solid; E-AIM, Clegg et al. (2006) - black dashed; E-ZSR, Clegg et al. (2004) - black dotted; (c) KIM: quasi-eutonic deliquescence regime - blue solid; gradual deliquescence regime - blue dashed; dilution regime - black solid; quasi-eutonic efflorescence regime - red solid.
I. The first section is a "quasi-eutonic deliquescence \& efflorescence regime", where all substances are just partly dissolved and exist also in a non-dissolved state and their aqueous phase concentrations correspond to apparent solubilities as defined and discussed above (Sect. 2.3):

In the "quasi-eutonic deliquescence regime" (Ia), the linear increase of $\kappa_{\mathrm{m}}$ with $G_{\mathrm{m}}$ starting from $\kappa_{\mathrm{m}}=0$ at $G_{\mathrm{m}}=1$ can be described by Eq. (26):

$$
\begin{aligned}
& \kappa_{\mathrm{m}}=\left(\left(\kappa_{\mathrm{MA}}^{0} C_{\mathrm{m}, \mathrm{MA}}^{\mathrm{ap}}+\kappa_{\mathrm{AS}}^{0} C_{\mathrm{AS}}^{\mathrm{ap}}\right)\right. \\
& +\left(\alpha_{\mathrm{MA}, \mathrm{AS}} C_{\mathrm{m}, \mathrm{MA}}^{\mathrm{ap}} C_{\mathrm{m}, \mathrm{AS}}^{\mathrm{ap}}\left(C_{\mathrm{m}, \mathrm{MA}}^{\mathrm{ap}}+C_{\mathrm{m}, \mathrm{AS}}^{\mathrm{ap}}\right)\right) \\
& \left.+\left(\alpha_{\mathrm{MA}}\left(C_{\mathrm{m}, \mathrm{MA}}^{\mathrm{ap}}\right)^{3}+\alpha_{\mathrm{AS}}\left(C_{\mathrm{m}, \mathrm{AS}}^{\mathrm{ap}}\right)^{3}\right)\right)\left(G_{\mathrm{m}}-1\right)(33)
\end{aligned}
$$

In the "quasi-eutonic efflorescence regime" (Ib), the linear decrease of $\kappa_{\mathrm{m}}$ with decreasing $G_{\mathrm{m}}$ towards $\kappa_{\mathrm{m}}=0$ at $G_{\mathrm{m}}=1$ can be also described by Eq. (33).

II. In the second section ("gradual deliquescence regime"), the dependence of $\kappa_{\mathrm{m}}$ on $G_{\mathrm{m}}$ can be described by Eq. (24), assuming that MA is fully dissolved and that AS undergoes gradual deliquescence:

$$
\begin{gathered}
\kappa_{\mathrm{m}}=\kappa_{\mathrm{MA}}^{0} f_{\mathrm{MA}}+\alpha_{\mathrm{MA}, \mathrm{AS}}\left(C_{\mathrm{m}, \mathrm{AS}}^{\mathrm{ap}}\right)^{2} f_{\mathrm{MA}} \\
+\left(\kappa_{\mathrm{AS}}^{0} C_{\mathrm{m}, \mathrm{AS}}^{\mathrm{ap}}+\alpha_{\mathrm{AS}}\left(C_{\mathrm{m}, \mathrm{AS}}^{\mathrm{ap}}\right)^{3}\right)\left(G_{\mathrm{m}}-1\right) \\
+\frac{\alpha_{\mathrm{MA}, \mathrm{AS}} f_{\mathrm{MA}}^{2} C_{\mathrm{m}, \mathrm{AS}}^{\mathrm{ap}}}{\left(G_{\mathrm{m}}-1\right)}+\frac{\alpha_{\mathrm{MA}} f_{\mathrm{MA}}^{3}}{\left(G_{\mathrm{m}}-1\right)^{2}},
\end{gathered}
$$

III. In the third section ("dilution regime"), the dependence of $\kappa_{\mathrm{m}}$ on $G_{\mathrm{m}}$ can be described by Eq. (27), assuming that both MA and AS are fully dissolved and undergo reversible dilution but no phase transition (reversible hygroscopic growth of fully deliquesced substances):

$$
\begin{aligned}
\kappa_{\mathrm{m}} & =\kappa_{\mathrm{MA}}^{0} f_{\mathrm{MA}}+\kappa_{\mathrm{AS}}^{0} f_{\mathrm{AS}} \\
& +\frac{\alpha_{\mathrm{MA}, \mathrm{AS}} f_{\mathrm{MA}} f_{\mathrm{AS}}+\alpha_{\mathrm{MA}} f_{\mathrm{MA}}^{3}+\alpha_{\mathrm{AS}} f_{\mathrm{AS}}^{3}}{\left(G_{\mathrm{m}}-1\right)^{2}}
\end{aligned}
$$

Using the dilute hygroscopicity and self-interaction parameters determined in single component experiments $\left(\kappa_{\mathrm{MA}}^{0}, \kappa_{\mathrm{AS}}^{0}\right.$, $\alpha_{\mathrm{MA}}, \alpha_{\mathrm{AS}}$; Table 3 ), we fitted Eqs. (33)-(35) to the data points in Fig. $5 \mathrm{c}$ and obtained the fit parameters specified in Table 4 . For the cross-interaction coefficient $\alpha_{\text {MA, AS }}$ we obtained two independent estimates from the gradual deliquescence regime (Eq. 34) and from the dilution regime (Eq. 35) that agree within statistical uncertainty $(-0.032$ vs. -0.031$)$. The apparent solubility of AS in the gradual deliquescence regime obtained by a fit of Eq. (34), $C_{\mathrm{m}, \mathrm{AS}}^{\mathrm{ap}}=0.70 \mathrm{~g} \mathrm{~g}^{-1}$, is close to the equilibrium solubility of pure crystalline AS 
Table 4. KIM fit parameters for mixed malonic acid - ammonium sulfate particles (MA-AS, mole ratio $1: 1$ ). $C_{\mathrm{m}, \mathrm{AS}}^{\mathrm{ap}}$ and $C_{\mathrm{m}, \mathrm{MA}}^{\mathrm{ap}}$ are the apparent solubilities of ammonium sulfate and malonic acid in the specified hygroscopicity regimes, $f_{\mathrm{AS}}$ and $f_{\mathrm{MA}}$ are the mass fractions of ammonium sulfate and malonic acid in the dry particle material, and $\alpha_{\mathrm{MA}, \mathrm{AS}}$ is the cross-interaction parameter. $n$ and $R^{2}$ are the number of data points and the coefficient of determination of each fit over the relevant range of mass growth factor $\left(G_{\mathrm{m}}\right)$.

\begin{tabular}{|c|c|c|c|c|c|c|}
\hline Regime & $G_{\mathrm{m}}$ range & $n$ & $R^{2}$ & Fit equation & Input parameter & Best fit parameter \pm standard error \\
\hline Quasi-eutonic deliquescence (Ia) & $1.00-1.04$ & 13 & 0.58 & 33 & $\begin{array}{l}C_{\mathrm{m}, \mathrm{AS}}^{\mathrm{ap}}=0.70 \mathrm{gg}^{-1} \\
\alpha_{\mathrm{MA}, \mathrm{AS}}=-0.032\end{array}$ & $C_{\mathrm{m}, \mathrm{MA}}^{\mathrm{ap}}=12.8 \pm 0.7 \mathrm{~g} \mathrm{~g}^{-1}$ \\
\hline Gradual deliquescence (II) & $1.04-1.81$ & 70 & 0.96 & 34 & $f_{\mathrm{MA}}=0.441$ & $\begin{array}{l}\alpha_{\mathrm{MA}, \mathrm{AS}}=-0.032 \pm 0.001 \\
C_{\mathrm{m}, \mathrm{AS}}^{\mathrm{ap}}=0.70 \pm 0.01 \mathrm{~g} \mathrm{~g}^{-1}\end{array}$ \\
\hline Dilution (III) & $1.10-4.68$ & 93 & 0.19 & 35 & $\begin{array}{l}f_{\mathrm{AS}}=0.559 \\
f_{\mathrm{MA}}=0.441\end{array}$ & $\alpha_{\mathrm{MA}, \mathrm{AS}}=-0.031 \pm 0.001$ \\
\hline Quasi-eutonic efflorescence (Ib) & $1.12-1.0$ & 15 & 0.84 & 33 & $\begin{array}{l}C_{\mathrm{m}, \mathrm{MA}}^{\mathrm{ap}}=12.8 \mathrm{~g} \mathrm{~g}^{-1} \\
\alpha_{\mathrm{MA}, \mathrm{AS}}=-0.032\end{array}$ & $C_{\mathrm{m}, \mathrm{AS}}^{\mathrm{ap}}=0.36 \pm 0.03 \mathrm{~g} \mathrm{~g}^{-1}$ \\
\hline
\end{tabular}

$\left(C_{\mathrm{m}, \mathrm{AS}}=0.76 \mathrm{gg}^{-1}\right.$, Table 3$)$. This confirms that the MAAS particles investigated by Choi and Chan (2002), Ling and Chan (2008), and Yeung and Chan (2010) contained AS in crystalline form. The apparent solubility of MA in the quasieutonic deliquescence regime obtained by a fit of Eq. (34) is $C_{\mathrm{m}, \mathrm{MA}}^{\mathrm{ap}}=12.8 \mathrm{~g} \mathrm{~g}^{-1}$, which is close to the apparent solubility of pure MA $\left(C_{\mathrm{m}, \mathrm{MA}}^{\mathrm{ap}}=13.3 \mathrm{~g} \mathrm{~g}^{-1}\right.$, Table 3$)$. However, in contrast to AS, it is an order of magnitude higher than the equilibrium solubility of pure crystalline $\mathrm{MA}\left(C_{\mathrm{m}, \mathrm{MA}}=\right.$ $1.58 \mathrm{~g} \mathrm{~g}^{-1}$, Table 3$)$ and the eutonic solubility of MA in crystalline MA-AS bulk samples $\left(C_{\mathrm{m}, \mathrm{MA}}^{\mathrm{eut}}=1.25 \mathrm{~g} \mathrm{~g}^{-1}\right.$; Brooks et al., 2002), which confirms that the MA-AS particles investigated by Choi and Chan (2002), Ling and Chan (2008), and Yeung and Chan (2010) contained MA in amorphous form (apparent solubility enhancement ratio $R_{\mathrm{ap}, \mathrm{MA}} \approx 8$ ). For the quasi-eutonic efflorescence regime, a fit of Eq. (33) with $C_{\mathrm{m}, \mathrm{MA}}^{\mathrm{ap}}=12.8 \mathrm{~g} \mathrm{~g}^{-1}$ yields $C_{\mathrm{m}, \mathrm{AS}}^{\mathrm{ap}}=0.36 \mathrm{~g} \mathrm{~g}^{-1}$, which is lower than the equilibrium solubility $\left(0.76 \mathrm{~g} \mathrm{~g}^{-1}\right)$ and apparent solubility $\left(2.44 \mathrm{~g} \mathrm{~g}^{-1}\right)$ of pure AS. One possible explanation of the low value of $C_{\mathrm{m}, \mathrm{AS}}^{\mathrm{ap}}$ obtained for the MA-AS system is partial crystallization of AS in the efflorescencemode experiment (Braban and Abbatt, 2004; Yeung and Chan, 2010), which decreases the total concentration of the AS in solution.

By inserting the hygroscopicity, solubility and interaction parameters from Tables 3 and 4 in Eqs. (33), (34), (35) combined with Eq. (10), we obtained the KIM model results displayed in Fig. 5a and b (solid lines). For the hygroscopic growth of fully deliquesced particles (aqueous droplets), the KIM results are in agreement with both the measurement data and the more complex E-AIM and E-ZSR multiparameter models (dashed and dotted lines). Moreover, KIM can also describe the early stages of water uptake and phase transitions in a mixture of crystalline inorganic and amorphous organic substances, which has not yet been possible with the more complex thermodynamic models as discussed in related studies (Clegg and Seinfeld, 2006; Ling and Chan, 2008; Tong et al., 2008; Yeung et al., 2009). Upon hydration, KIM Eqs. (10) and (33) predict a stepwise onset of water absorption (quasi-eutonic deliquescence) at $37 \% \mathrm{RH}$ in agreement with the experimental data (insert in Fig. 5a). From the intersect of the gradual deliquescence curve (Eqs. 10 and 34) with the dilution curve (Eqs. 10 and 35) follows an RH threshold of $74 \%$ for complete deliquescence in agreement with the measurement data and E-ZSR model results (Clegg and Seinfeld, 2006). Upon dehydration, KIM Eqs. (10) and (33) predict an efflorescence threshold of $23 \% \mathrm{RH}$ in agreement with the experimental data (insert in Fig. 5b).

\subsection{Atmospheric aerosol samples}

Figure $6 \mathrm{a}$ and $\mathrm{b}$ show the mass growth factors observed as a function of relative humidity upon hydration and dehydration of the atmospheric aerosol samples collected in the tropical rainforest of Amazonia near Manaus, Brazil (AMAZE) and in the boreal forest region near St. Petersburg, Russia (SPB) as detailed in Table 2 and Sect. 3.1. Both samples exhibit gradual and fully reversible water uptake similar to the behavior of amorphous organic substances (Mikhailov et al., 2009).

From the measurement data displayed in Fig. 6a and b we derived mass-based hygroscopicity parameters as outlined in Appendix C, using Eq. (C2). The corresponding plots of $\kappa_{\mathrm{m}}$ vs. $G_{\mathrm{m}}$ are shown in Fig. $6 \mathrm{c}$ for the AMAZE sample and in Fig. 6d for the SPB sample. In both cases, the observed dependence of $\kappa_{\mathrm{m}}$ on $G_{\mathrm{m}}$ exhibits three distinctly different sections or regimes of hygroscopicity. In the first section (quasi-eutonic regime, I) $\kappa_{\mathrm{m}}$ increases linearly with $G_{\mathrm{m}}$, which can be described by Eq. (26) assuming quasi-eutonic conditions where multiple solutes co-exist in the partly dissolved state and their aqueous phase concentrations correspond to apparent solubilities $\left(C_{\mathrm{m}, i}^{\mathrm{ap}}\right)$. In the second section (gradually deliquescent regime, II), $\kappa_{\mathrm{m}}$ exhibits a non-linear 

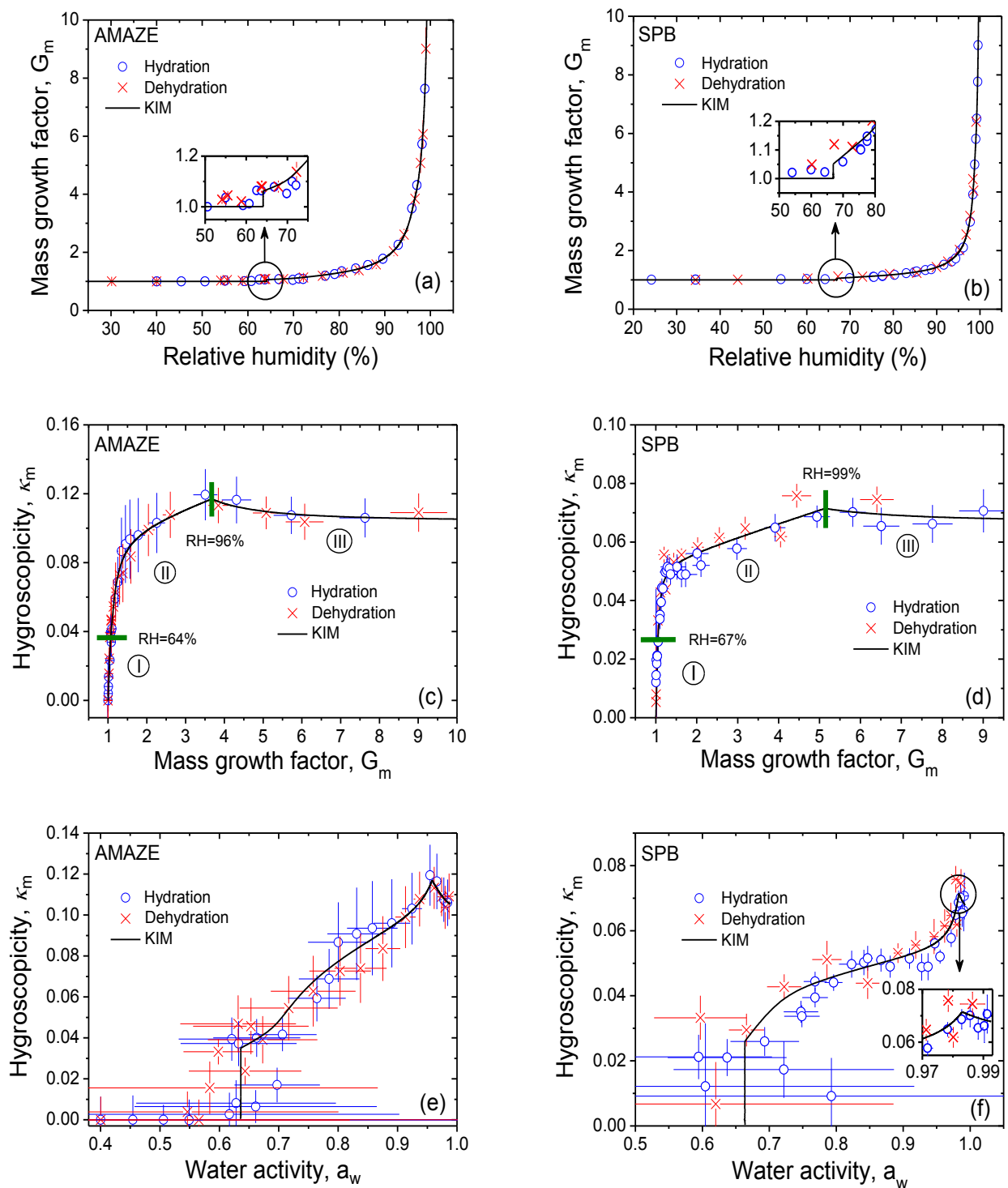

Fig. 6. Hygroscopic properties of atmospheric aerosol samples from tropical rainforest air (AMAZE) and boreal rural air (SPB, Table 2): (a, b) mass growth factors $\left(G_{\mathrm{m}}\right)$ observed as a function of relative humidity compared to KIM; (c, d) mass-based hygroscopicity parameters $\left(\kappa_{\mathrm{m}}\right)$ calculated as a function of mass growth factor (Appendix C, Eq. C2); and (e, f) mass based hygroscopicity parameters $\left(\kappa_{\mathrm{m}}\right)$ plotted against water activity. The data points and error bars (mean value \pm standard deviation) are from FDHA experiments of hydration (blue circles) and dehydration (red crosses). The black lines are fits of KIM Eqs. (36)-(38). The labels I, II, and III indicate different regimes of hygroscopicity; the borders of the corresponding fit intervals are indicated by green bars $(\mathbf{c}, \mathbf{d})$.

increase with $G_{\mathrm{m}}$ which can be described by Eq. (23) assuming gradual dissolution of multiple water soluble compounds with different solubilities $\left(C_{\mathrm{m}, i}^{\mathrm{ap}}\right)$. In the third section (dilute regime, III), $\kappa_{\mathrm{m}}$ decreases with increasing $G_{\mathrm{m}}$ and becomes concentration-independent at very high values of $G_{\mathrm{m}}$. This behavior is analogous to the behavior observed for aqueous solutions of pure substances (Fig. 2c, d; Fig. 4b) and it can be described by Eq. (27) assuming that the water-soluble fraction of the aerosol sample is fully dissolved.

The individual physico-chemical parameters involved in Eqs. (23), (26) and (27) are not readily available for at- mospheric aerosol samples consisting of multiple chemical components with unknown molecular structures and properties. Nevertheless, Eqs. (26), (23) and (27) can be re-written as follows to fit the observed dependencies of $\kappa_{\mathrm{m}}$ on $G_{\mathrm{m}}$ in the different regimes of hygroscopicity:

Regime I (quasi-eutonic deliquescence/efflorescence):

$\kappa_{\mathrm{m}}=k_{1}\left(G_{\mathrm{m}}-1\right)$

Regime II (gradual deliquescence/efflorescence):

$\kappa_{\mathrm{m}}=k_{2}+k_{3}\left(G_{\mathrm{m}}-1\right)+k_{4}\left(G_{\mathrm{m}}-1\right)^{-1}+k_{5}\left(G_{\mathrm{m}}-1\right)^{-2}$ 
Table 5. KIM fit parameters for the atmospheric aerosol samples collected in the Amazon (AMAZE) and in St. Petersburg (SPB). $n$ and $R^{2}$ are the number of data points and the coefficient of determination of the fit.

\begin{tabular}{lllllll}
\hline Sample & Regime & $\begin{array}{l}G_{\mathrm{m}} \\
\text { range }\end{array}$ & $n$ & $R^{2}$ & $\begin{array}{l}\text { Fit } \\
\text { equation }\end{array}$ & $\begin{array}{l}\text { Best fit parameter } \\
\pm \text { standard error }\end{array}$ \\
\hline \multirow{2}{*}{ AMAZE } & Quasi-eutonic deliquescence \& efflorescence (I) & $1-1.06$ & 14 & 0.94 & 36 & $k_{1}=0.57 \pm 0.02$ \\
\cline { 2 - 6 } & Gradual deliquescence \& efflorescence (II) & $1.06-3.6$ & 24 & 0.98 & 37 & $\begin{array}{l}k_{2}=0.098 \pm 0.004 ; \\
k_{4}=-0.082 \pm 0.001 ; k_{5}(\mathrm{II})=2.7 \times 10^{-4} \pm 5 \times 10^{-5}\end{array}$ \\
\cline { 2 - 6 } & Dilution (III) & $3.6-9$ & 8 & 0.72 & 38 & $\begin{array}{l}k_{5} \text { (III) }=0.091 \pm 0.021 ; \\
k_{6}=0.104 \pm 0.002\end{array}$ \\
\hline SPB & Quasi-eutonic deliquescence \& efflorescence (I) & $1-1.05$ & 11 & 0.65 & 36 & $k_{1}=0.51 \pm 0.05$ \\
\cline { 2 - 6 } & Gradual deliquescence \& efflorescence (II) & $1.05-5.14$ & 11 & 0.82 & 37 & $\begin{array}{l}k_{2}=0.053 \pm 0.002 ; k_{3}=4.55 \times 10^{-3} \pm 7.7 \times 10^{-4} \\
k_{4}=-1.47 \times 10^{-3} \pm 5.5 \times 10^{-4} ; k_{5} \text { (II) }=1.0 \times 10^{-5} \pm 3 \times 10^{-5}\end{array}$ \\
\cline { 2 - 6 } & Dilution (III) & $5.14-9.1$ & 7 & 0.10 & 38 & $k_{5}$ (III) $=0.079 \pm 0.062 ; k_{6}=0.067 \pm 0.003$ \\
\end{tabular}

Regime III (dilution):

$\kappa_{\mathrm{m}}=k_{5}\left(G_{\mathrm{m}}-1\right)^{-2}+k_{6}$

Here $k_{1}$ to $k_{6}$ are fit parameters related to the solubility and interaction coefficients defined in Sect. 2.3:

$$
\begin{aligned}
k_{1} & =\sum_{i \in \mathrm{pd}} \kappa_{\mathrm{m}, i}^{0} C_{\mathrm{m}, i}^{\mathrm{ap}}+\sum_{i \in \mathrm{pd}}\left(C_{\mathrm{m}, i}^{\mathrm{ap}}\right)^{2} \sum_{\substack{j \in \mathrm{pd}, j>i}} \alpha_{i j} C_{\mathrm{m}, i}^{\mathrm{ap}} \\
& +\sum_{i \in \mathrm{pd}} \alpha_{i i}\left(C_{\mathrm{m}, i}^{\mathrm{ap}}\right)^{3} \\
k_{2} & =\sum_{i \in \mathrm{pd}}\left(C_{\mathrm{m}, i}^{\mathrm{ap}}\right)^{2} \sum_{\substack{j \in \mathrm{pd}, j>i}} \alpha_{i j} f_{j}+\sum_{i \in \mathrm{pd}} \kappa_{\mathrm{m}, i}^{0} f_{i} \\
k_{3} & =\sum_{i \in \mathrm{pd}} \kappa_{\mathrm{m}, i}^{0} C_{\mathrm{m}, i}^{\mathrm{ap}}+\sum_{i \in \mathrm{pd}}\left(C_{\mathrm{m}, i}^{\mathrm{ap}}\right)^{2} \sum_{\substack{j \in \mathrm{pd}, j>i}} \alpha_{i j} C_{\mathrm{m}, j}^{\mathrm{ap}} \\
& +\sum_{i \in \mathrm{pd}} \alpha_{i i}\left(C_{\mathrm{m}, i}^{3}\right)
\end{aligned}
$$$$
k_{4}=\sum_{i \in \mathrm{fd}} f_{i}^{2} \sum_{\substack{j \in \mathrm{pd}, j>i}} \alpha_{i j} C_{\mathrm{m}, j}^{\mathrm{ap}}
$$$$
k_{5}=\sum_{i \in \mathrm{fd}} f_{i}^{2} \sum_{\substack{j \in \mathrm{fd}, j>i}} \alpha_{i j} f_{j}
$$

$k_{6}=\sum_{i \in \mathrm{fd}} \kappa_{\mathrm{m}, i}^{0} f_{i}$

The fit parameter $k_{5}$ occurs in both Eq. (37) for regime II and Eq. (38) for regime III. Note, however, that the fit parameter values of $k_{5}$ can differ between regimes II and III, because the number of species in the aqueous phase can be different upon deliquescence $\left(k_{5}(\mathrm{II})\right)$ and under dilute conditions $\left(k_{5}(\mathrm{III})\right)$. According to Eq. (17), the fit parameter $k_{6}$ can be regarded as the dilute hygroscopicity parameter of the investigated sample of particulate matter $\left(\kappa_{\mathrm{m}}^{0}\right)$. The other fit parameters include interaction coefficients and solubilities.

The lines in Fig. 6c and d are fits of KIM Eqs. (36)-(38) to the experimental data, and the corresponding best fit parameters $k_{1}-k_{6}$ are listed in Table 5 . The mostly high coefficients of determination $\left(R^{2}\right)$ confirm that the KIM approach can be used to describe the concentration dependence of the hygroscopicity of multi-component atmospheric aerosol samples. In spite of the very different origin of the two investigated atmospheric aerosol samples, most of the best fit parameter values were of similar magnitude.

Figure $6 \mathrm{e}$ and $\mathrm{f}$ show the hygroscopicity parameter $\kappa_{\mathrm{m}}$ as function of water activity. The data points were obtained by inserting the corresponding pairs of $G_{\mathrm{m}}-\kappa_{\mathrm{m}}$ values from Fig. $6 \mathrm{c}$ and $d$ in Eq. (10). The model lines were obtained by inserting Eqs. (35)-(37) with the fit parameters from Table 5 in Eq. (10). Again the three sections I, II, and III reflect different regimes of hygroscopicity. For the quasi-eutonic regime (I), the combination of Eq. (10) and Eq. (36) yields a constant water activity value given by $a_{\mathrm{w}}=\left(k_{1}+1\right)^{-1}$. This relation yields the following quasi-eutonic RH values characterizing the onset of deliquescence: $64 \%$ for the AMAZE sample and $67 \%$ for the SPB sample.

At and below the quasi-eutonic RH, the observed mass growth factors are close to unity (Fig. 6a and b). Thus, the $\pm 1 \%$ uncertainty in $G_{\mathrm{m}}$ translates into $\sim 100 \%$ uncertainty in $G_{\mathrm{m}}-1$, which propagates further into large relative uncertainties of $a_{\mathrm{w}}$ as calculated from Eq. (10) (large horizontal error bars of the data points in the quasi-eutonic regime of Fig. 6e and f). This issue has already been discussed by Kreidenweis et al. (2008).

The gradual-deliquescence regime (II) extends up to $96 \%$ $\mathrm{RH}$ for the AMAZE sample and even further up to $99 \% \mathrm{RH}$ for the SPB sample. Gradual deliquescence over an extended range of RH is typical for mixed multi-component particles that begin to take up water vapor at a eutonic RH value and continue to grow with increasing RH up to full dissolution of 
all particle components (Wexler and Seinfeld, 1991; Martin et al., 2000; Clegg et al., 2001; Mikhailov et al., 2009).

In the dilution regime (III), the characteristic decrease of $\kappa_{\mathrm{m}}$ with increasing $a_{\mathrm{w}}$ is relatively steep for the AMAZE sample $\left(\mathrm{d} \ln \kappa_{\mathrm{m}} / \mathrm{d} \ln a_{\mathrm{w}}=4\right)$ and rather small for the SPB sample $\left(\mathrm{d} \ln \kappa_{\mathrm{m}} / \mathrm{d} \ln a_{\mathrm{w}}=0.5\right)$. The steep slope reflects a high value of the fit parameter $k_{5}$ (III), which in turn indicates strong interaction between the solute molecules in the AMAZE sample consisting mostly of SOA and small amounts of inorganic ions $(\sim 10-20 \%)$ (Eq. 40, Table 5) (Martin et al., 2010; Pöschl et al., 2010).

\subsection{Closure between hygroscopic growth and $\mathrm{CCN}$ activation}

In this section we test the applicability of our mass-based hygroscopicity parameter interaction model and FDHA data for closure between hygroscopic growth and CCN measurements. We used the dilute hygroscopicity parameters obtained with KIM Eq. (29) (Table 3) and Eq. (44) $\left(\kappa_{\mathrm{m}}^{0}=k_{6}\right.$, Table 5) to predict the conditions of $\mathrm{CCN}$ activation. To calculate critical dry diameters of $\mathrm{CCN}$ activation $\left(D_{\mathrm{d}, \mathrm{c}}\right)$ as a function of water vapor supersaturation $\left(S_{\mathrm{w}}\right)$ we inserted $\kappa_{\mathrm{m}}^{0}$ in the simplified Köhler model (Eq. 15) using $\rho_{\mathrm{w}}=$ $1.0 \mathrm{~g} \mathrm{~cm}^{-3}, \rho_{\mathrm{d}}=2.165 \mathrm{~g} \mathrm{~cm}^{-3}$ for $\mathrm{NaCl}, \rho_{\mathrm{d}}=1.769 \mathrm{~g} \mathrm{~cm}^{-3}$ for AS. For the AMAZE sample an approximate average density of $1.3 \mathrm{~g} \mathrm{~cm}^{-3}$ was estimated based on Eq. (7) using the volume-based hygroscopicity $\kappa_{\mathrm{v}}=0.132$ (Gunthe et al., 2009, Table 2, CCN retrieved) and $\kappa_{\mathrm{m}}^{0}=k_{6}=0.104$ (Table 5). A density of $1.5 \mathrm{~g} \mathrm{~cm}^{-3}$ was used for the SPB sample (Virtanen et al., 2006).

Figure $7 \mathrm{a}$ and $\mathrm{b}$ show the relationship between the critical dry diameter of CCN activation and water vapor supersaturation for $\mathrm{NaCl}$ and $\mathrm{AS}$ particles predicted with KIM. For comparison the relationship is also calculated based on a full Köhler model (Köhler model AP3 of Rose et al., 2008) using the AIM for the parameterization of the water activity. The two model lines agree well with each other and show only small differences ( $4 \%$ at $S=0.3 \%$ for $\mathrm{NaCl}$ and $5 \%$ at $S=1.2 \%$ for AS). These differences are still much smaller than the differences between several experimental data obtained from direct CCN measurements (Raymond and Pandis, 2002; Giebl et al., 2002; Corrigan and Novakov, 1999; Rose et al., 2008) or derived from HTDMA measurements (Kreidenweis et al., 2005).

Figure $7 \mathrm{c}$ shows the relationship between the critical dry diameter of $\mathrm{CCN}$ activation and water vapor supersaturation for atmospheric aerosol particles predicted with KIM. For the AMAZE sample, the model predictions are in good agreement with the results of size-resolved CCN measurements (Gunthe et al., 2009) averaged over the same period as the filter sampling time (Table 2). The KIM model line falls within the error bars (standard deviations) of the experimental data points. The grey shaded area around the model line shows that uncertainties in particle density have limited
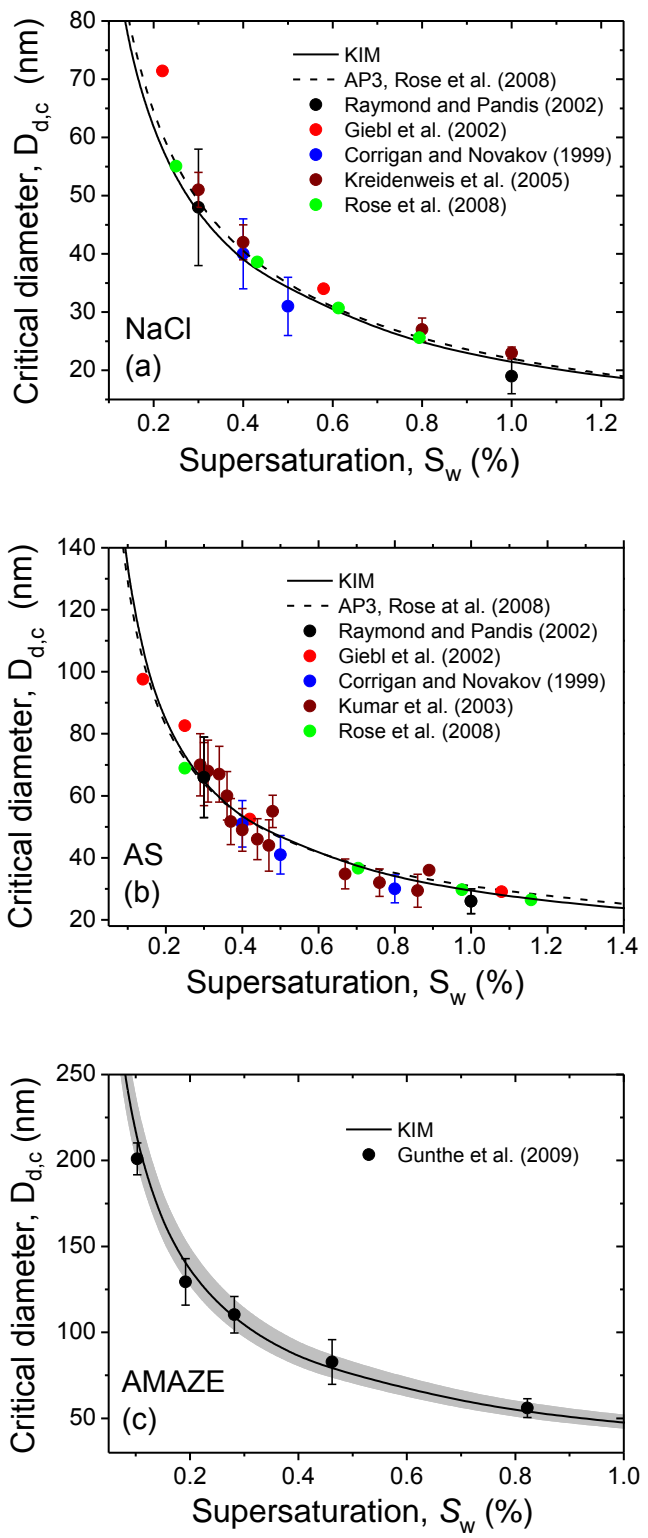

Fig. 7. Critical dry diameters of CCN activation for sodium chloride $(\mathrm{NaCl})$, ammonium sulfate (AS) and atmospheric aerosol samples (AMAZE) as a function of water vapor supersaturation according to Köhler theory. Solid lines are KIM model predictions based on FDHA measurement results $\left(\kappa_{\mathrm{m}}^{0}\right.$ inserted in Eq. 15). (a, b) Predictions for $\mathrm{NaCl}$ and $\mathrm{AS}$ are compared against a detailed reference model (dashed lines: AIM/AP3, Rose et al., 2008) and literature data from HTDMA measurements (Kreidenweis et al., 2005) or direct $\mathrm{CCN}$ activation measurements (other studies). (c) Predictions for the Amazonian aerosol sample (AMAZE) are compared against $\mathrm{CCN}$ measurement data recorded while the filter sample was collected (arithmetic mean \pm standard deviation). The gray shaded area denotes the uncertainty range of prediction related to particle density: center line assuming $\rho_{\mathrm{d}}=1.3 \mathrm{~g} \mathrm{~cm}^{-3}$, top bound with $\rho_{\mathrm{d}}=1.0 \mathrm{~g} \mathrm{~cm}^{-3}$ and low bound with $\rho_{\mathrm{d}}=1.6 \mathrm{~g} \mathrm{~cm}^{-3}$. 
Table 6. $\mathrm{CCN}$ parameters for the reference salt samples $\left(\mathrm{NaCl},\left(\mathrm{NH}_{4}\right)_{2} \mathrm{SO}_{4}\right)$ and for the atmospheric aerosol samples (AMAZE, SPB). $\kappa_{\mathrm{m}}^{0}$ $\left(=k_{6}\right)$ is the dilute hygroscopicity parameter (Eq. 44$), \rho_{\mathrm{d}}$ is the particle density, $\beta$ is the scaling parameter and $D_{\mathrm{d}, \mathrm{c}}$ is the dry activation diameter calculated from Eq. (15) for water vapor supersaturations $\left(S_{\mathrm{W}}\right)$ of $0.2 \%$ and $0.8 \%$.

\begin{tabular}{llllll}
\hline Sample & $\kappa_{\mathrm{m}}^{0}$ & $\begin{array}{l}\rho_{\mathrm{d}} \\
\left(\mathrm{g} \mathrm{cm}^{-3}\right)\end{array}$ & $\begin{array}{l}\beta \\
\left(\mathrm{nm}^{-1}\right)\end{array}$ & $\begin{array}{l}D_{\text {d.c }}(\mathrm{nm}) \\
S_{\mathrm{w}}=0.2 \%\end{array}$ & $\begin{array}{l}D_{\text {d.c }}(\mathrm{nm}) \\
S_{\mathrm{w}}=0.8 \%\end{array}$ \\
\hline $\mathrm{NaCl}$ & 0.68 & 2.165 & 21.09 & 61.8 & 24.9 \\
$\left(\mathrm{NH}_{4}\right)_{2} \mathrm{SO}_{4}(\mathrm{AS})$ & 0.32 & 1.769 & 28.87 & 84.6 & 34.1 \\
$\mathrm{AMAZE}$ & 0.104 & 1.3 & 46.63 & 136.3 & 54.10 \\
$\mathrm{SPB}$ & 0.067 & 1.5 & 51.52 & 150.6 & 59.8 \\
\hline
\end{tabular}

influence on the prediction of critical dry diameters for $\mathrm{CCN}$ activation: relative variations of $\rho_{\mathrm{d}}\left(1.3 \pm 0.3 \mathrm{~g} \mathrm{~cm}^{-3}\right)$ lead to relative variations of $\pm \sim 6 \%$ in the dry activation diameter. For the SPB sample no CCN measurement data were available, but the lower value of $\kappa_{\mathrm{m}}^{0}(-35 \%$ relative to AMAZE) implies higher activation diameter values $(+10 \%$ relative to AMAZE; Table 6).

Overall, Fig. 7 demonstrates that the mass-based hygroscopicity interaction model (KIM) is well-suited to link hygroscopic growth measurement data to $\mathrm{CCN}$ measurement data. The good agreement can be explained by the fact that the parameter value $\kappa_{\mathrm{m}}=\kappa_{\mathrm{m}}^{0}$ inserted in Eq. (15) represents the dilute hygroscopicity, which captures the characteristics of water uptake by dilute solution droplets as formed upon $\mathrm{CCN}$ activation.

\section{Summary and conclusions}

In this manuscript, we present a mass-based hygroscopicity parameter model approach for efficient description of concentration-dependent water uptake by pure and mixed particles including multi-component atmospheric aerosols. It can be directly used for the analysis of water uptake experiments measuring the mass of absorbed water: electrodynamic balance (EDB), particle mass analyzer (Khalizov et al., 2009), microbalance (Hatch et al., 2008), micro-Raman spectroscopy (Yeung and Chan, 2008), and filter-based techniques (Mikhailov et al., 2011; Speer et al., 2003; Lee and Hsu, 2000).

The KIM framework enables the analysis and prediction of the hygroscopic growth and phase transitions of particles with complex chemical composition. It can be applied to systems containing organic and inorganic compounds that are in amorphous and metastable states.
Equations (6)-(10) define the mass-based hygroscopicity parameter $\kappa_{\mathrm{m}}$, which is equivalent to the volume-based hygroscopicity parameter introduced by Petters and Kreidenweis (2007) but independent of deviations from volume additivity. Equations (12)-(15) describe a simple Köhler model in which $\kappa_{\mathrm{m}}$ can be used to predict the particle critical diameter for activation to a cloud droplet.

In Eqs. (16)-(24) we develop a $\kappa_{\mathrm{m}}$-interaction model (KIM) that combines a dilute hygroscopicity parameter with additional self- and cross-interaction parameters describing non-ideal solution behavior and concentration dependencies of single- and multi-component systems. For specific conditions, the main model equation (Eq. 23) can be reduced to simplified versions (Eqs. 26-27).

For particles consisting of a single organic or inorganic solute (MA, LG, NaCl, AS), Eqs. (28)-(31) provide a simple two-parameter approach (dilute hygroscopicity and selfinteraction) that yields a good fit to experimental data and is in agreement with more complex multi-parameter reference models (AIM, E-AIM; Figs. 2-4). Binary mixtures of organic and inorganic solutes (MA-AS) are described by Eqs. (33)-(35) with five parameters (dilute hygroscopicities, selfand cross-interactions) providing a good fit to experimental data. Compared to established reference models (E-AIM, EZSR), the KIM approach agrees for fully deliquesced particles and is actually better suited for partially dissolved particles (gradual deliquescence, Fig. 5), taking into account apparent or equilibrium solubilities.

By application of KIM to FDHA measurement data of atmospheric aerosol samples, we can distinguish three different regimes of hygroscopicity: (I) a quasi-eutonic regime at low-humidity $(<\sim 70 \% \mathrm{RH})$ where the solutes co-exist in aqueous and solid phases (Eq.36); (II) a gradual deliquescence regime at intermediate humidity $(\sim 70 \%$ to $\sim 96-$ $99 \% \mathrm{RH}$ ) where different solutes undergo gradual dissolution in the aqueous phase (Eq. 37); and (III) a dilute regime at high humidity ( $>$ 96-99\% RH) where the solutes are fully dissolved approaching their dilute hygroscopicity (Eq. 38).

In each of these regimes, the concentration dependence of $\kappa_{\mathrm{m}}$ can be described by simplified model equations (Eqs. 3638) based on observable mass growth factors and a total of only six fit parameters $\left(k_{1}-k_{6}\right)$ summarizing the combined 
effects of the dilute hygroscopicity parameters, self- and cross-interaction parameters, and solubilities of all involved chemical components. The parameter $k_{6}$ determined by fitting of Eq. (38) to hygroscopic growth data obtained in the dilute regime at high humidity represents the dilute hygroscopicity of the aerosol $\left(\kappa_{\mathrm{m}}^{0}\right)$ and can be used to predict $\mathrm{CCN}$ activation diameters as a function of water vapor supersaturation. For sodium chloride and ammonium sulfate reference particles as well as for pristine rainforest aerosols consisting mostly of secondary organic matter, we obtained good agreement between the KIM predicted critical dry diameters and directly measured dry particle activation diameters.

We are not aware of any other model that would be able and has been applied to describe the different regimes of hygroscopicity observed in our FDHA measurements and outlined above. The application of KIM and mass-based measurement techniques shall help to bridge gaps in the current understanding of water uptake by atmospheric aerosols: (1) the gap between hygroscopicity parameters determined by hygroscopic growth measurements under sub-saturated conditions and by CCN activation measurements at water vapor supersaturation, and (2) the gap between the results of simplified single parameter models widely used in atmospheric or climate science and the results of complex multiparameter ion- and molecule-interaction models frequently used in physical chemistry and solution thermodynamics.

\section{Appendix A}

\section{Critical supersaturation and dry diameter of $\mathrm{CCN}$ activation}

To calculate the critical values of water vapor supersaturation and particle dry diameter, KIM (Eq. 12) can be rewritten as follows:

$$
\begin{aligned}
s_{\mathrm{w}} & =\left(\frac{\kappa_{\mathrm{m}}}{G_{\mathrm{m}}-1}+1\right)^{-1} \exp \left(\frac{A}{D_{\mathrm{d}}}\left[\frac{\rho_{\mathrm{w}}}{\rho_{\mathrm{d}} G_{\mathrm{m}}}\right]^{1 / 3}\right) \text { with } \\
A & =\frac{4 \sigma_{\mathrm{w}} M_{\mathrm{w}}}{R T \rho_{\mathrm{w}}} .
\end{aligned}
$$

Taking the logarithm of Eq. (A1) and considering $\ln (x+1) \approx x$ for small $x$ yields:

$$
\begin{aligned}
\ln s_{\mathrm{w}} & =\ln \left(\frac{\kappa_{\mathrm{m}}}{G_{\mathrm{m}}-1}+1\right)^{-1}+\frac{A}{D_{\mathrm{d}}}\left[\frac{\rho_{\mathrm{w}}}{\rho_{\mathrm{d}} G_{\mathrm{m}}}\right]^{1 / 3} \\
& =-\ln \left(\frac{\kappa_{\mathrm{m}}}{G_{\mathrm{m}}-1}+1\right)+\frac{A}{D_{\mathrm{d}}}\left[\frac{\rho_{\mathrm{w}}}{\rho_{\mathrm{d}} G_{\mathrm{m}}}\right]^{1 / 3} \\
& \approx-\frac{\kappa_{\mathrm{m}}}{G_{\mathrm{m}}-1}+\frac{A}{D_{\mathrm{d}}}\left[\frac{\rho_{\mathrm{w}}}{\rho_{\mathrm{d}} G_{\mathrm{m}}}\right]^{1 / 3}
\end{aligned}
$$

For dilute solutions, $G_{\mathrm{m}}-1 \approx G_{\mathrm{m}}$ leads to

$$
\ln s_{\mathrm{w}}=-\frac{\kappa_{\mathrm{m}}}{G_{\mathrm{m}}}+\frac{A}{D_{\mathrm{d}}}\left[\frac{\rho_{\mathrm{w}}}{\rho_{\mathrm{d}} G_{\mathrm{m}}}\right]^{1 / 3}
$$

The derivation of Eq. (A3) yields

$$
\frac{d \ln s_{\mathrm{w}}}{d G_{\mathrm{m}}}=\frac{\kappa_{\mathrm{m}}}{G_{\mathrm{m}}^{2}}-\frac{1}{3} \frac{A}{D_{\mathrm{d}}}\left(\frac{\rho_{\mathrm{w}}}{\rho_{\mathrm{d}}}\right)^{1 / 3} .
$$

To determine the maximum of Eq. (A3), Eq. (A4) is set to zero, and the critical value of $G_{\mathrm{m}}$ is calculated:

$$
\begin{aligned}
\frac{d \ln s_{\mathrm{w}}}{d G_{\mathrm{m}}} & =\frac{\kappa_{\mathrm{m}}}{G_{\mathrm{m}}^{2}}-\frac{1}{3} \frac{A}{D_{\mathrm{d}}}\left(\frac{\rho_{\mathrm{w}}}{\rho_{\mathrm{d}}}\right)^{1 / 3} \\
G_{\mathrm{m}}^{-4 / 3} & =0 \\
G_{\mathrm{m}, \mathrm{c}} & =\left(\frac{3 \kappa_{\mathrm{m}} D_{\mathrm{d}}}{A}\right)^{3 / 2}\left(\frac{\rho_{\mathrm{d}}}{\rho_{\mathrm{w}}}\right)^{1 / 2}
\end{aligned}
$$

To get the critical water vapor saturation ratio of $\mathrm{CCN}$ activation, $s_{\mathrm{w}, \mathrm{c}}$, we substitute Eq. (A5) into Eq. (A2):

$$
\begin{aligned}
& \ln s_{\mathrm{w}, \mathrm{c}}=-\frac{\kappa_{\mathrm{m}}}{\left(\frac{3 \kappa_{\mathrm{m}} D_{\mathrm{d}}}{A}\right)^{3 / 2}}\left(\frac{\rho_{\mathrm{w}}}{\rho_{\mathrm{d}}}\right)^{1 / 2}+\frac{A}{D_{\mathrm{d}}}\left(\frac{\rho_{\mathrm{w}}}{\rho_{\mathrm{d}}}\right)^{1 / 3} \\
& {\left[\left(\frac{3 \kappa_{\mathrm{m}} D_{\mathrm{d}}}{A}\right)^{3 / 2}\left(\frac{\rho_{\mathrm{d}}}{\rho_{\mathrm{w}}}\right)^{1 / 2}\right]^{-1 / 3}=\left(\frac{A}{D_{\mathrm{d}}}\right)^{3 / 2}\left(\frac{\rho_{\mathrm{w}}}{\rho_{\mathrm{d}}}\right)^{1 / 2}\left(3 \kappa_{\mathrm{m}}\right)^{-1 / 2}} \\
& -\left(\frac{A}{D_{\mathrm{d}}}\right)^{3 / 2} \kappa_{\mathrm{m}}\left(3 \kappa_{\mathrm{m}}\right)^{-3 / 2}\left(\frac{\rho_{\mathrm{w}}}{\rho_{\mathrm{d}}}\right)^{1 / 2}= \\
& =\left(\frac{A}{D_{\mathrm{d}}}\right)^{3 / 2}\left(\frac{\rho_{\mathrm{w}}}{\rho_{\mathrm{d}}}\right)^{1 / 2}\left(3 \kappa_{\mathrm{m}}\right)^{-1 / 2}\left[1-\frac{\kappa_{\mathrm{m}}}{3 \kappa_{\mathrm{m}}}\right]
\end{aligned}
$$

It follows,

$$
\ln s_{\mathrm{w}, \mathrm{c}}=\frac{2}{3}\left(\frac{A}{D_{\mathrm{d}}}\right)^{3 / 2}\left(\frac{\rho_{\mathrm{w}}}{3 \kappa_{\mathrm{m}} \rho_{\mathrm{d}}}\right)^{1 / 2}
$$

or

$s_{\mathrm{w}, \mathrm{c}}=\exp \left[\frac{2}{3}\left(\frac{A}{D_{\mathrm{d}}}\right)^{3 / 2}\left(\frac{\rho_{\mathrm{w}}}{3 \kappa_{\mathrm{m}} \rho_{\mathrm{d}}}\right)^{1 / 2}\right]$

Transforming Eq. (A6) considering that $e^{x} \approx x+1$ for small $x$ leads to

$$
\begin{aligned}
s_{\mathrm{w}, \mathrm{c}} & =\exp \left[\frac{2}{3}\left(\frac{A}{D_{\mathrm{d}}}\right)^{3 / 2}\left(\frac{\rho_{\mathrm{w}}}{3 \kappa_{\mathrm{m}} \rho_{\mathrm{d}}}\right)^{1 / 2}\right] \\
& =\frac{2}{3}\left(\frac{A}{D_{\mathrm{d}}}\right)^{3 / 2}\left(\frac{\rho_{\mathrm{w}}}{3 \kappa_{\mathrm{m}} \rho_{\mathrm{d}}}\right)^{1 / 2}+1
\end{aligned}
$$

Combining Eq. (A7) with $S_{\mathrm{w}}(\%)=\left(s_{\mathrm{W}}-1\right) \cdot 100 \%$ yields:

$$
S_{\mathrm{w}}(\%)=\frac{2}{3}\left(\frac{A}{D_{\mathrm{d}}}\right)^{3 / 2}\left(\frac{\rho_{\mathrm{w}}}{3 \kappa_{\mathrm{m}} \rho_{\mathrm{d}}}\right)^{1 / 2} \times 100 \% \text {. }
$$

Further transformation of Eq. (A8) yields the critical dry diameter of CCN activation, $D_{\mathrm{d}, \mathrm{c}}$ :

$$
\begin{aligned}
D_{\mathrm{d}, \mathrm{c}} & =\left[\frac{100 \%}{S_{\mathrm{w}}} A^{3 / 2} \frac{2}{3}\left(\frac{\rho_{\mathrm{w}}}{3 \kappa_{\mathrm{m}} \rho_{\mathrm{d}}}\right)^{1 / 2}\right]^{2 / 3} \\
& =A\left(\frac{100 \%}{S_{\mathrm{w}}}\right)^{2 / 3}\left(\frac{2}{3}\right)^{2 / 3}\left(\frac{\rho_{\mathrm{w}}}{3 \kappa_{\mathrm{m}} \rho_{\mathrm{d}}}\right)^{1 / 3} \\
& =A\left(\frac{4}{27} \frac{\rho_{\mathrm{w}}}{\kappa_{\mathrm{m}} \rho_{\mathrm{d}}}\right)^{1 / 3}\left(\frac{S_{\mathrm{w}}}{100 \%}\right)^{-2 / 3}
\end{aligned}
$$


or

$D_{\text {d.c }}=\beta \times S_{\mathrm{w}}^{-2 / 3}$

where $\beta=A\left(\frac{4}{27} \frac{\rho_{\mathrm{w}}}{\kappa_{\mathrm{m}} \rho_{\mathrm{d}}}\right)^{1 / 3}\left(\frac{1}{100 \%}\right)^{-2 / 3}$.

\section{Appendix B}

Relations between KIM, the osmotic coefficient and the extended ZSR model approach for multicomponent solutions

The water activity and the osmotic coefficient $\phi$ of a multicomponent solution are related by the expression (Clegg et al., 2001)

$\ln a_{\mathrm{w}}=-M_{\mathrm{w}} \phi \sum_{j} \mu_{j}=-M_{\mathrm{w}} \phi \frac{\sum_{j} n_{j}}{m_{\mathrm{w}}}$,

where the summation goes over the molality $\mu_{j}$ or mole number $n_{j}$ of all solute species (ions and molecules). From the definition of $\kappa_{\mathrm{m}}$ (Eq. 6) follows:

$\frac{1}{m_{\mathrm{W}}}=\left(\frac{1-a_{\mathrm{w}}}{a_{\mathrm{w}}}\right) \frac{1}{\kappa_{\mathrm{m}} m_{\mathrm{d}}}$

Inserting the right-hand side of Eq. (B2) into Eq. (B1) and re-arranging Eq. (B2) relative to $\kappa_{\mathrm{m}}$ we obtain explicit relation between mass-based hygroscopicity parameter and regular osmotic coefficient:

$\kappa_{\mathrm{m}}=-\frac{M_{\mathrm{w}}}{M_{\mathrm{d}}} \phi \frac{\left(1-a_{\mathrm{w}}\right)}{a_{\mathrm{w}} \ln a_{\mathrm{w}}}$,

where $M_{\mathrm{d}}=m_{\mathrm{d}} / \sum_{j} n_{j}$ is the effective molecular mass of mixed dry particle.

For dilute solution the term $\left(1-a_{\mathrm{w}}\right) /\left(a_{\mathrm{w}} \ln a_{\mathrm{w}}\right)$ approaches -1 and Eq. (B3) reduced to

$\kappa_{\mathrm{m}} \approx \kappa_{\mathrm{m}}^{0} \approx \frac{M_{\mathrm{w}}}{M_{\mathrm{d}}} \phi$

Equation (B4) shows that the dilute hygroscopicity, $\kappa_{\mathrm{m}}^{0}$, is simply the osmotic coefficient of solution scaled by the ratio of the molar masses of water and solute.

In case of a multicomponent system the extended ZSR expression for the total mass of water at water activity, $a_{\mathrm{w}}$, is given by the relation (Kirgintsev and Luk' yanov, 1966; Clegg et al., 2003):

$m_{\mathrm{w}}=\sum_{i} w_{i}^{0}+\left(\sum_{i} n_{i}\right) \sum_{i} \sum_{j>i} x_{i} x_{j}\left(A_{i, j}^{0}+A_{i j}^{1} \lambda_{i j}+B_{i j} a_{\mathrm{w}}\right)$,

where $w_{i}^{0}$ mass of water in pure solution of solute $i$ at water activity $a_{\mathrm{w}}, n_{i}$ is the number of moles of species $i$, $x_{i}=n_{i} / \sum_{i} n_{i}$ is the dry mole fraction of a solute $i$ (similarly for $\left.x_{j}\right)$, and also $\lambda_{i j}=n_{j} /\left(n_{i}+n_{j}\right), A^{0}, A^{1}$ and $B$ are the empirical fit parameters for mixture.
Equation (B2) can be combined with Eq. (21) to obtain the respective expression for total mass of water based on the KIM :

$$
\begin{aligned}
m_{\mathrm{w}} & =\frac{a_{\mathrm{w}}}{1-a_{\mathrm{w}}} m_{\mathrm{d}}\left(\sum_{i} \kappa_{\mathrm{m}, i}^{0} c_{\mathrm{m}, i}+\sum_{i} \sum_{j>i} \alpha_{i j} c_{\mathrm{m}, i} c_{\mathrm{m}, j}\right. \\
& \left.+\sum_{i} \alpha_{i i} c_{\mathrm{m}, i}^{2}\right)
\end{aligned}
$$

Equation (B5) and Eq. (B6) demonstrate the basic differences between KIM and ZSR models.

In the KIM one cross interaction parameters $\left(\alpha_{i j}\right)$ is used for every pair of solute, while in the ZSR model three empirical fit parameters are taken into account. It should also be mentioned that in the extended ZSR model the concentration effect of pure solution of the solute is not considered. The term $\sum_{i} w_{i}^{0}$ in Eq. (B5) assumes semi-ideal behavior where every solute may interact with the solvent but not with each other (Stokes and Robinson, 1966). The KIM contains the self-interaction coefficient $\left(\alpha_{i i}\right)$, which takes into account these pair interactions.

That is important for hygroscopic modeling in highly concentrated (supersaturated) solutions both for pure and for mixed particles.

From Eq. (B2), Eq. (B5) the explicit relationship between KIM and the extended ZSR model can be obtained

$\kappa_{\mathrm{m}}=\frac{1-a_{\mathrm{w}}}{a_{\mathrm{w}}} \frac{1}{m_{\mathrm{d}}}$

$\left(\sum_{i} w_{i}^{0}+\left(\sum_{i} n_{i}\right) \sum_{i} \sum_{j>i} x_{i} x_{j}\left(A_{i, j}^{0}+A_{i j}^{1} \lambda_{i j}+B_{i j} a_{\mathrm{w}}\right)\right)$

\section{Appendix C}

\section{Kelvin correction}

In this study submicron polydisperse aerosols were sampled and analyzed with the FDHA method. When calculating $\kappa_{\mathrm{m}}$ from the hygroscopic growth of polydisperse particles the Kelvin effect has to be taken into account. Therefore, the following iterative procedure was utilized to calculate $\kappa_{\mathrm{m}}$.

The initial $\kappa_{\mathrm{m}}^{\text {init }}$ was determined from Eq. (C1) (equivalent to Eq. 10) at a given relative humidity, $s_{\mathrm{W}}$, and mass growth factor, $G_{\mathrm{m}}$ :

$\kappa_{\mathrm{m}}^{\mathrm{init}}=\left(\frac{1}{s_{\mathrm{W}}}-1\right)\left(G_{\mathrm{m}}-1\right) \quad$ (under assumption that

$s_{\mathrm{W}}=a_{\mathrm{w}}$, i.e., without Kelvin effect)

Based on Eq. (12) including the Kelvin effect, $\kappa_{\mathrm{m}}$ can be written as

$\kappa_{\mathrm{m}}=\left(\frac{\exp \left(\frac{4 \sigma_{\mathrm{w}} M_{\mathrm{w}}}{R T \rho_{\mathrm{w}} D_{\mathrm{d}, i}}\left[\frac{\rho_{\mathrm{w}}}{\rho_{\mathrm{d}} G_{\mathrm{m}, i}}\right]^{1 / 3}\right)}{s_{\mathrm{W}}}-1\right)\left(G_{\mathrm{m}, i}-1\right)$. 
Then $G_{\mathrm{m}, i}$ was calculated using Eq. (C2) for the dry diameter, $D_{\mathrm{d}, i}$ of each size fraction of aerosol at given $\kappa_{\mathrm{m}}$. Thus, we can obtain the wet mass, $m\left(D_{i}\right)$ of each aerosol fraction as follows:

$m\left(D_{i}\right)=m_{\mathrm{d}, i} G_{\mathrm{m}, i} N\left(D_{\mathrm{d}, i}\right)$,

where $m_{\mathrm{d}, i}=D_{\mathrm{d}, i} \rho_{\mathrm{d}}$ is the mass of dry particle, and $N\left(D_{\mathrm{d}, i}\right)$ is the concentration of the particles of a given dry size, $D_{\mathrm{d}, i}$.

The total mass growth factor can be written as

$G_{\mathrm{m}, \mathrm{tot}}=\frac{\sum_{i} m\left(D_{i}\right)}{\sum m_{\mathrm{d}, i} N\left(D_{\mathrm{d}, i}\right)}$

The mass-based hygroscopicity parameter $\kappa_{\mathrm{m}}$ in Eq. (C2) is varied iteratively until the measured mass growth factor $\left(G_{\mathrm{m}}\right)$ is in coincidence with the calculated value $\left(G_{\mathrm{m}, \text { tot }}\right)$. The obtained $\kappa_{\mathrm{m}}$ values are shown in Fig. 2c, d and Fig. $6 \mathrm{c}$, d and were used for the model fit.

To convert the modeled $G_{\mathrm{m}}\left(a_{\mathrm{w}}\right)$ into a $G_{\mathrm{m}}(\mathrm{RH})$ dependence we transformed Eq. (12) as follows:

$D_{\text {eff }}=\frac{4 \sigma_{\mathrm{w}} M_{\mathrm{w}}}{R T \rho_{\mathrm{w}}}\left(\frac{\rho_{\mathrm{w}}}{\rho_{\mathrm{d}} G_{\mathrm{m}}}\right)^{1 / 3} \ln \left\{s_{\mathrm{w}}\left(\frac{\kappa_{\mathrm{m}}}{G_{\mathrm{m}}-1}\right)+1\right\}$,

where $D_{\text {eff }}$ is the effective diameter of quasi-monodisperse particles with the size corrected value of $\kappa_{\mathrm{m}}$ (Eq. C2) at the given experimental mass growth factor $G_{\mathrm{m}}$.

The obtained values of $D_{\text {eff }}( \pm$ st. dev.) are $98.5(1.5) \mathrm{nm}$ for $\mathrm{NaCl} ; 171(5) \mathrm{nm}$ for AS; 193(9) nm for the SPB and 233(8) nm for the AMAZE sample.

These values were used to compare experimental data with KIM calculations (Fig. 2a, b and Fig. 6a, b).

For the literature data of MA, LG and MA-AS no Kelvin correction was applied since in EDB and Raman experiments the particle diameter was varied in the range of $10-30 \mu \mathrm{m}$.

Acknowledgements. Corresponding authorship is shared by E. Mikhailov (eugene.mikhailov@paloma.spbu.ru) and D. Rose (d.rose@mpic.de). This work has been supported by the Max Planck Society (MPG), the Russian Foundation for Basic Research (grant 12-05-00620-a), the German Research Foundation (DFG-SPP 1294-HALO, grant PO 1013/2), and the European Commission under the integrated projects EUCAARI (grant 036833-2) and PEGASOS (grant 265148). The authors thank M. O. Andreae, P. Artaxo, S. T. Martin, S. S. Gunthe and the entire AMAZE-08 team for support; C. K. Chan and his group at the Hong Kong University of Science and Technology for electrodynamic balance and micro-Raman spectroscopy data; and the team of the "Geomodel" Research Center at the Saint-Petersburg State University for help with scanning electron microscopy.

The service charges for this open access publication have been covered by the Max Planck Society.

Edited by: B. Ervens

\section{References}

Bilde, M. and Svenningsson, B.: CCN activation of slightly soluble organics: the importance of small amounts of inorganic salt and particle phase, Tellus B, 56, 128-134, 2004.

Biskos, G., Paulsen, D., Russell, L. M., Buseck, P. R., and Martin, S. T.: Prompt deliquescence and efflorescence of aerosol nanoparticles, Atmos. Chem. Phys., 6, 4633-4642, doi:10.5194/acp-64633-2006, 2006.

Braban, C. F. and Abbatt, J. P. D.: A study of the phase transition behavior of internally mixed ammonium sulfate - malonic acid aerosols, Atmos. Chem. Phys., 4, 1451-1459, doi:10.5194/acp4-1451-2004, 2004.

Brooks, S. D., Wise, M. E., Cushing, M., and Tolbert, M. A.: Deliquescence of organic/ammonium sulfate aerosol, Geophys. Res. Lett., 29, 1917, doi:10.1029/2002GL014733, 2002.

Carrico, C. M., Petters, M. D., Kreidenweis, S. M., Sullivan, A. P., McMeeking, G. R., Levin, E. J. T., Engling, G., Malm, W. C., and Collett Jr., J. L.: Water uptake and chemical composition of fresh aerosols generated in open burning of biomass, Atmos. Chem. Phys., 10, 5165-5178, doi:10.5194/acp-10-5165-2010, 2010.

Cerully, K. M., Raatikainen, T., Lance, S., Tkacik, D., Tiitta, P., Petäjä, T., Ehn, M., Kulmala, M., Worsnop, D. R., Laaksonen, A., Smith, J. N., and Nenes, A.: Aerosol hygroscopicity and CCN activation kinetics in a boreal forest environment during the 2007 EUCAARI campaign, Atmos. Chem. Phys., 11, 12369-12386, doi:10.5194/acp-11-12369-2011, 2011.

Chan, M. N., Choi, M. Y., Ng, N. L., and Chan, C. K.: Hygroscopicity of water-soluble organic compounds in atmospheric aerosols: Amino acids and biomass burning derived organic species, Environ. Sci. Technol., 39, 1555-1562, doi:10.1021/es0495841, 2005.

Chen, Q., Farmer, D. K., Schneider, J., Zorn, S. R., Heald, C. L., Karl, T. G., Guenther, A., Allan, J. D., Robinson, N., Coe, H., Kimmel, J. R., Pauliquevis, T., Borrmann, S., Pöschl, U., Andreae, M. O., Artaxo, P., Jimenez, J. L., and Martin, S. T.: Mass spectral characterization of submicron biogenic organic particles in the Amazon Basin, Geophys. Res. Lett., 36, L20806, doi:10.1029/2009GL039880, 2009.

Choi, M. Y. and Chan, C. K.: The effects of organic species on the hygroscopic behaviors of inorganic aerosols, Environ. Sci. Technol., 36, 2422-2428, doi:10.1021/es0113293, 2002.

Ciobanu, V. G., Marcolli, C., Krieger, U. K., Zuend, A., and Peter, T.: Efflorescence of ammonium sulfate and coated ammonium sulfate particles: evidence for surface nucleation, J. Phys. Chem. A, 114, 9486-9495, 2010.

Clarke, E. C. W. and Glew, D. N.: Evaluation of the thermodynamic functions for aqueous sodium chloride from equilibrium and calorimetric measurements below $154^{\circ} \mathrm{C}$, J. Phys. Chem. Ref. Data, 14, 489-609, 1985.

Clegg, S. L. and Seinfeld, J. H.: Improvement of the ZdanovskiiStokes-Robinson model for mixtures containing solutes of different charge types, J. Phys. Chem. A, 108, 1008-1017, 2004.

Clegg, S. L. and Seinfeld, J. H.: Thermodynamic models of aqueous solutions containing inorganic electrolytes and dicarboxylic Acids at $298.15 \mathrm{~K}$. 1. The acids as nondissociating components, J. Phys. Chem. A., 110, 5692-5717, 2006.

Clegg, S. L., Brimblecombe, P., and Wexler, A. S.: A thermodynamic model of the system $\mathrm{H}^{+}-\mathrm{NH}_{4}^{+}-\mathrm{Na}^{+}-\mathrm{SO}_{4}^{2-}-\mathrm{NO}_{3}^{-}-\mathrm{Cl}^{-}$. $\mathrm{H}_{2} \mathrm{O}$ at 298.15 K, J. Phys. Chem. A., 102, 2155-2171, 1998. 
Clegg, S. L., Seinfeld, J. H., and Brimblecombe, P.: Thermodynamic modelling of aqueous aerosols containing electrolytes and dissolved organic compounds, Aerosol Sci., 32, 713-738, doi:10.1016/S0021-8502(00)00105-1, 2001.

Clegg, S. L., Seinfeld, J. H., and Edney E. O.: Thermodynamic modelling of aqueous aerosols containing electrolytes and dissolved organic compounds. II. An extended Zdanovskii-StokesRobinson approach, Aerosol Sci., 34, 667-690, 2003.

Corrigan, C. E. and Novakov, T.: Cloud condensation nucleus activity of organic compounds: a laboratory study, Atmos. Environ., 33, 2661-2668, doi:10.1016/S1352-2310(98)00310-0, 1999.

Duplissy, J., DeCarlo, P. F., Dommen, J., Alfarra, M. R., Metzger, A., Barmpadimos, I., Prevot, A. S. H., Weingartner, E., Tritscher, T., Gysel, M., Aiken, A. C., Jimenez, J. L., Canagaratna, M. R., Worsnop, D. R., Collins, D. R., Tomlinson, J., and Baltensperger, U.: Relating hygroscopicity and composition of organic aerosol particulate matter, Atmos. Chem. Phys., 11, 11551165, doi:10.5194/acp-11-1155-2011, 2011.

Fitzgerald, J. W.: Dependence of supersaturation spectrum of CCN on aerosol size distribution and composition, J. Atmos. Sci., 30, 628-634, 1973.

Flatau, P. J., Walko, R. L., and Cotton, W. R.: Polynomial fits to saturation vapor pressure, J. Appl. Meteorology, 31, 1507-1513, 1992.

Fors, E. O., Swietlicki, E., Svenningsson, B., Kristensson, A., Frank, G. P., and Sporre, M.: Hygroscopic properties of the ambient aerosol in southern Sweden - a two year study, Atmos. Chem. Phys., 11, 8343-8361, doi:10.5194/acp-11-8343-2011, 2011.

Fredenslund, A., Jones, R. L., and Prausnitz, J. M.: Groupcontribution estimation of activity coefficients in nonideal liquid mixtures, AIChE J., 21, 1086-1099, 1975.

Gao, Y., Chen, B. C., and Yu, L. T.: Efflorescence relative humidity of airborne sodium chloride particles: A theoretical investigation, Atmos. Environ., 41, 2019-2023, 2007.

Giebl, H., Berner, A., Reischl, G., Puxbaum, H., Kasper-Giebl, A., and Hitzenberger, R.: CCN activation of oxalic and malonic acid test aerosols with the University of Vienna cloud condensation nuclei counter, J. Aerosol Sci., 33, 1623-1634, doi:10.1016/S0021-8502(02)00115-5, 2002.

Good, N., Topping, D. O., Allan, J. D., Flynn, M., Fuentes, E., Irwin, M., Williams, P. I., Coe, H., and McFiggans, G.: Consistency between parameterisations of aerosol hygroscopicity and CCN activity during the RHaMBLe discovery cruise, Atmos. Chem. Phys., 10, 3189-3203, doi:10.5194/acp-10-3189-2010, 2010a.

Good, N., Topping, D. O., Duplissy, J., Gysel, M., Meyer, N. K., Metzger, A., Turner, S. F., Baltensperger, U., Ristovski, Z., Weingartner, E., Coe, H., and McFiggans, G.: Widening the gap between measurement and modelling of secondary organic aerosol properties?, Atmos. Chem. Phys., 10, 2577-2593, doi:10.5194/acp-10-2577-2010, 2010 b.

Gunthe, S. S., King, S. M., Rose, D., Chen, Q., Roldin, P., Farmer, D. K., Jimenez, J. L., Artaxo, P., Andreae, M. O., Martin, S. T., and Pöschl, U.: Cloud condensation nuclei in pristine tropical rainforest air of Amazonia: size-resolved measurements and modeling of atmospheric aerosol composition and CCN activity, Atmos. Chem. Phys., 9, 7551-7575, doi:10.5194/acp-9-75512009,2009
Gunthe, S. S., Rose, D., Su, H., Garland, R. M., Achtert, P., Nowak, A., Wiedensohler, A., Kuwata, M., Takegawa, N., Kondo, Y., Hu, M., Shao, M., Zhu, T., Andreae, M. O., and Pöschl, U.: Cloud condensation nuclei $(\mathrm{CCN})$ from fresh and aged air pollution in the megacity region of Beijing, Atmos. Chem. Phys., 11, 1102311039, doi:10.5194/acp-11-11023-2011, 2011.

Gysel, M., Weingartner, E., and Baltensperger, U.: Hygroscopicity of aerosol particles at low temperatures. 2. Theoretical and experimental hygroscopic properties of laboratory generated aerosols, Environ. Sci. Technol., 36, 63-68, doi:10.1021/es010055g, 2002.

Gysel, M., Weingartner, E., Nyeki, S., Paulsen, D., Baltensperger, U., Galambos, I., and Kiss, G.: Hygroscopic properties of watersoluble matter and humic-like organics in atmospheric fine aerosol, Atmos. Chem. Phys., 4, 35-50, doi:10.5194/acp-4-352004, 2004.

Hancock, B. C. and Parks, M.: What is the true solubility advantage for amorphous pharmaceuticals?, Pharm. Res., 17, 397-404, 2000.

Hansen, H. K., Rasmussen, P., Fredenslund, A., Schiller, M., and Gmebling, J.: Vapor-liquid equilibria by UNIFAC group contribution. 5. Revision and extension, Ind. Eng. Chem. Res., 30, 2352-2355, 1991.

Hatch, C. D., Gierlus, K. M. Schuttlefield, J. D., and Grassian V. H.: Water adsorption and cloud condensation nuclei activity of calcite and calcite coated with model humic and fulvic acids, Atmos. Environ., 42, 5672-5684, 2008.

Huff Hartz, K. E., Rosenørn, T., Ferchak, S. R., Raymond, T. M., Bilde, M., Donahue, N. M., and Pandis, S. N.: Cloud condensation nuclei activation of monoterpene and sesquiterpene secondary organic aerosol, J. Geophys. Res., 110, D14208, doi:10.1029/2004JD005754, 2005.

Irwin, M., Good, N., Crosier, J., Choularton, T. W., and McFiggans, G.: Reconciliation of measurements of hygroscopic growth and critical supersaturation of aerosol particles in central Germany, Atmos. Chem. Phys., 10, 11737-11752, doi:10.5194/acp10-11737-2010, 2010.

Junge, C. and McLaren, E.: Relationship of cloud nuclei spectra to aerosol size distribution and composition, J. Atmos. Sci., 28, 382-390, 1971.

Khalizov, A. F, Zhang, R., Zhang, D., Xue, H., Pagels, J., and McMurry, P. H.: Formation of highly hygroscopic soot aerosols upon internal mixing with sulfuric acid vapor, J. Geophys. Res., 114, D05208, doi:10.1029/2008JD010595, 2009.

Kirgintsev, A. and Luk'yanov, A. V.: Isopiestic investigations of ternary solutions. VIII. General treatment of the results for 34 ternary aqueous salt solutions, Russian Journal of Physical Chemistry, 40, 953-956, 1966

Krämer, L., Pöschl, U., and Niessner, R.: Microstructural rearrangement of sodium chloride condensation aerosol particles on interaction with water vapor, J. Aerosol. Sci., 31, 673-685, doi:10.1016/S0021-8502(99)00551-0, 2000.

Kreidenweis, S. M., Koehler, K., DeMott, P. J., Prenni, A. J., Carrico, C., and Ervens, B.: Water activity and activation diameters from hygroscopicity data - Part I: Theory and application to inorganic salts, Atmos. Chem. Phys., 5, 1357-1370, doi:10.5194/acp-5-1357-2005, 2005.

Kreidenweis, S. M., Petters, M. D., and DeMott, P. J.: Singleparameter estimates of aerosol water content, Environ. Res. Lett., 3, 035002, doi:10.1088/1748-9326/3/3/035002, 2008. 
Kuhlbusch, T. A. J., Hertlein, A.-M., and Schütz, L. W.: Sources, determination, monitoring, and transport of carbonaceous aerosols in Mainz, Germany, Atmos. Environ., 32, 1097-1110, 1998.

Kulmala, M., Laaksonen, A., Charlson, R. J., and Korhonen, P.: Clouds without supersaturation, Nature, 388, 336-337, 1997.

Laaksonen, A., Korhonen, P., Kulmala, M., and Charlson, R. J. :Modification of the Köhler equation to include soluble trace gases and slightly soluble substances, J. Atmos. Sci., 55, 853862, 1998.

Lee, C. T. and Hsu, W. C.: The measurement of liquid water mass associated with collected hygroscopic particles, Aerosol Sci., 31, 189-197, 2000.

Ling, T. Y. and Chan, C. K.: Partial crystallization and deliquescence of particles containing ammonium sulfate and dicarboxylic acids, J. Geophys. Res., 113, D14205, doi:10.1029/2008JD009779, 2008.

Marcolli, C. and Krieger, U. K..: Phase changes during hygroscopic cycles of mixed organic/inorganic model systems of tropospheric aerosols, J. Phys. Chem. A., 110, 1881-1893, doi:10.1021/jp0556759, 2006.

Marcolli, C., Luo, B., and Peter, T.: Mixing of the organic aerosol fractions: Liquids as the thermodynamically stable phases, J. Phys. Chem. A., 108, 2216-2224, doi:10.1021/jp0360801, 2004.

Martin, S. T.: Phase transitions of aqueous atmospheric particles, Chem. Rev., 100, 3403-3453, doi:10.1021/cr990034t, 2000.

Martin, S. T., Andreae, M. O., Althausen, D., Artaxo, P., Baars, H., Borrmann, S., Chen, Q., Farmer, D. K., Guenther, A., Gunthe, S. S., Jimenez, J. L., Karl, T., Longo, K., Manzi, A., Müller, T., Pauliquevis, T., Petters, M. D., Prenni, A. J., Pöschl, U., Rizzo, L. V., Schneider, J., Smith, J. N., Swietlicki, E., Tota, J., Wang, J., Wiedensohler, A., and Zorn, S. R.: An overview of the Amazonian Aerosol Characterization Experiment 2008 (AMAZE08), Atmos. Chem. Phys., 10, 11415-11438, doi:10.5194/acp10-11415-2010, 2010.

Mayol-Bracero, O. L., Guyon, P., Graham, B., Roberts, G., and Andreae, M. O.: Water-soluble organic compounds in biomass burning aerosols over Amazonia. 2. Apportionment of the chemical composition and importance of the polyacidic fraction, J. Geophys. Res., 107, 8091, doi:10.1029/2001JD000522, 2002.

McFiggans, G., Artaxo, P., Baltensperger, U., Coe, H., Facchini, M. C., Feingold, G., Fuzzi, S., Gysel, M., Laaksonen, A., Lohmann, U., Mentel, T. F., Murphy, D. M., O’Dowd, C. D., Snider, J. R., and Weingartner, E.: The effect of physical and chemical aerosol properties on warm cloud droplet activation, Atmos. Chem. Phys., 6, 2593-2649, doi:10.5194/acp-6-2593-2006, 2006.

McGlashan, M. L.: Deviations from Raoult's law, J. Chem. Educ., 40, 516-518, 1963

Metzger, S., Steil, B., Xu, L., Penner, J. E., and Lelieveld, J.: New representation of water activity based on a single solute specific constant to parameterize the hygroscopic growth of aerosols in atmospheric models, Atmos. Chem. Phys., 12, 5429-5446, doi:10.5194/acp-12-5429-2012, 2012.

Mikhailov, E., Vlasenko, S., Niessner, R., and Pöschl, U.: Interaction of aerosol particles composed of protein and saltswith water vapor: hygroscopic growth and microstructural rearrangement, Atmos. Chem. Phys., 4, 323-350, doi:10.5194/acp-4-323-2004, 2004.

Mikhailov, E., Vlasenko, S., Martin, S. T., Koop, T., and Pöschl, U.: Amorphous and crystalline aerosol particles interacting with water vapor: conceptual framework and experimental evidence for restructuring, phase transitions and kinetic limitations, Atmos. Chem. Phys., 9, 9491-9522, doi:10.5194/acp-9-9491-2009, 2009.

Mikhailov, E. F., Merkulov, V. V., Vlasenko, S. S., and Pöschl, U. Filter-based differential hygroscopicity analyzer, Izvestya Atmospheric and Oceanic Physics, 47, 747-759, 2011.

Mitchell, R. I. and Pilcher, J. M.: Improved cascade impactor for measuring aerosol particle sizes, Industrial and Engineering Chemistry, 51, 1039-1042, 1959.

Mochida, M., Kuwata, M., Miyakawa, T., Takegawa, N., Kawamura, K., and Kondo, Y.: Relationship between hygroscopicity and cloud condensation nuclei activity for urban aerosols in Tokyo, J. Geophys. Res., 111, D23204, doi:10.1029/2005JD006980, 2006.

Mosharraf, M. and Nyström, C.: The effect of dry mixing on the apparent solubility of hydrophobic, sparingly soluble drugs, Europ. J. Pharm. Sci., 9, 145-156, 1999.

Murdande, S. B., Pikal, M. J., Shanker, R. M., and Bogner, R. H.: Solubility advantage of amorphous pharmaceuticals, II. Application of quantitative thermodynamic relationships for prediction of solubility enhancement in structurally diverse insoluble pharmaceuticals, Pharm. Res., 27, 2704-2714, 2010.

Murdande, S. B., Pikal, M. J., Shanker, R. M., and Bogner, R. H. Aqueous solubility of crystalline and amorphous drugs: challenges in measurement, Pharm. Develop. Technol., 16, 187-200, 2011.

Peng, C., Chan M. N., and Chan, C. K.: The hygroscopic properties of dicarboxylic and multifunctional acids: Measurements and UNIFAC predictions, Environ. Sci. Technol., 35, 4495-4501, 2001.

Petters, M. D. and Kreidenweis, S. M.: A single parameter representation of hygroscopic growth and cloud condensation nucleus activity, Atmos. Chem. Phys., 7, 1961-1971, doi:10.5194/acp-71961-2007, 2007.

Petters, M. D. and Kreidenweis, S. M.: A single parameter representation of hygroscopic growth and cloud condensation nucleus activity - Part 2: Including solubility, Atmos. Chem. Phys., 8, 6273-6279, doi:10.5194/acp-8-6273-2008, 2008

Petters, M. D., Carrico, C. M., Kreidenweis, S. M., Prenni, A. J., DeMott, P. J., Collett, J. L., and Moosmüller, H.: Cloud condensation nucleation activity of biomass burning aerosol, J. Geophys. Res., 114, D22205, doi:10.1029/2009JD012353, 2009.

Pöschl, U., Martin, S. T., Sinha, B., Chen, Q., Gunthe, S. S., Huffman, J. A., Borrmann, S., Farmer, D. K., Garland, R. M., Helas, G., Jimenez, J.L., King, S. M., Manzi, A., Mikhailov, E., Pauliquevis, T., Petters, M. D., Prenni, A. J., Roldin, P., Rose, D., Schneider, J., Su, H., Zorn, S. R., Artaxo, P., and Andreae, M. O.: Rainforest Aerosols as Biogenic Nuclei of Clouds and Precipitation in the Amazon, Science, 329, 15131516, doi:10.1126/science.1191056, 2010.

Pringle, K. J., Tost, H., Pozzer, A., Pöschl, U., and Lelieveld, J.: Global distribution of the effective aerosol hygroscopicity parameter for CCN activation, Atmos. Chem. Phys., 10, 52415255, doi:10.5194/acp-10-5241-2010, 2010.

Pruppacher, H. R. and Klett, J. D.: Microphysics of clouds and precipitation, Kluwer Academic Publishers, Dordrecht, 2000.

Raymond T. M. and Pandis S. N.: Cloud activation of singlecomponent organic aerosol particles, J. Geophys. Res., 107, 
4787, doi:10.1029/2002JD002159, 2002.

Raymond, T. M. and Pandis, S. N.: Formation of cloud droplets by multicomponent organic particles, J. Geophys. Res., 108, 4469, doi:10.1029/2003JD003503, 2003.

Rissler, J., Swietlicki, E., Zhou, J., Roberts, G., Andreae, M. O., Gatti, L. V., and Artaxo, P.: Physical properties of the submicrometer aerosol over the Amazon rain forest during the wetto-dry season transition - comparison of modeled and measured CCN concentrations, Atmos. Chem. Phys., 4, 2119-2143, doi:10.5194/acp-4-2119-2004, 2004.

Roberts, G. C., Day, D. A., Russell, L. M., Dunlea, E. J., Jimenez, J. L., Tomlinson, J. M., Collins, D. R., Shinozuka, Y., and Clarke, A. D.: Characterization of particle cloud droplet activity and composition in the free troposphere and the boundary layer during INTEX-B, Atmos. Chem. Phys., 10, 6627-6644, doi:10.5194/acp-10-6627-2010, 2010.

Rose, D., Gunthe, S. S., Mikhailov, E., Frank, G. P., Dusek, U., Andreae, M. O., and Pöschl, U.: Calibration and measurement uncertainties of a continuous-flow cloud condensation nuclei counter (DMT-CCNC): CCN activation of ammonium sulfate and sodium chloride aerosol particles in theory and experiment, Atmos. Chem. Phys., 8, 1153-1179, doi:10.5194/acp-8-11532008, 2008.

Rose, D., Nowak, A., Achtert, P., Wiedensohler, A., Hu, M., Shao, M., Zhang, Y., Andreae, M. O., and Pöschl, U.: Cloud condensation nuclei in polluted air and biomass burning smoke near the mega-city Guangzhou, China - Part 1: Size-resolved measurements and implications for the modeling of aerosol particle hygroscopicity and CCN activity, Atmos. Chem. Phys., 10, 33653383, doi:10.5194/acp-10-3365-2010, 2010.

Rose, D., Gunthe, S. S., Su, H., Garland, R. M., Yang, H., Berghof, M., Cheng, Y. F., Wehner, B., Achtert, P., Nowak, A., Wiedensohler, A., Takegawa, N., Kondo, Y., Hu, M., Zhang, Y., Andreae, M. O., and Pöschl, U.: Cloud condensation nuclei in polluted air and biomass burning smoke near the mega-city Guangzhou, China - Part 2: Size-resolved aerosol chemical composition, diurnal cycles, and externally mixed weakly $\mathrm{CCN}$-active soot particles, Atmos. Chem. Phys., 11, 2817-2836, doi:10.5194/acp-112817-2011, 2011.

Seinfeld, J. H. and Pandis, S. N.: Atmospheric Chemistry and Physics: From Air Pollution to Climate Change, John Wiley and Sons, Inc., New York, 2006.

Setschenov, J.: Über die Konstitution der Salzlösungen aufgrund ihres Verhaltens zu Kohlensäure, Z. Phys. Chem., 4, 117-125, 1889.

Shulman, M. L., Jacobson, M. C., Carlson, R. J., Synovec, R. E., and Young, T. E.: Dissolution behavior and surface tension effects of organic compounds in nucleating cloud droplets, Geophys. Res. Lett., 23, 277-280, doi:10.1029/95GL03810, 1996.

Sjogren, S., Gysel, M., Weingartner, E., Baltensperger, U., Cubison, M. J., Coe, H., Zardini, A. A., Marcolli, C., Krieger, U. R., and Peter, T.: Hygroscopic growth and water uptake kinetics of twophase aerosol particles consisting of ammonium sulphate, adipic and humic acid mixtures, J. Aerosol Sci., 38, 157-171, 2007.

Speer, R. E., Edney, E. O., and Kleindenst, T. E.: Impact of organic compounds on the concentrations of liquid water in ambient PM2:5, Aerosol Sci., 34, 63-77, 2003.

Stephen, H. and Stephen, T. (Eds.): Solubilities of inorganic and organic compounds, Pergamon Press, Oxford, 1963.
Stokes, R. H. and Robinson, R. A.: Interactions in aqueous nonelectrolyte solutions: I. Solute-solvent equilibria, J. Phys. Chem., 70, 2126-2130, 1966.

Sullivan, R. C., Moore, M. J. K., Petters, M. D., Kreidenweis, S. M., Roberts, G. C., and Prather, K. A.: Effect of chemical mixing state on the hygroscopicity and cloud nucleation properties of calcium mineral dust particles, Atmos. Chem. Phys., 9, 33033316, doi:10.5194/acp-9-3303-2009, 2009.

Svenningsson, B., Rissler, J., Swietlicki, E., Mircea, M., Bilde, M., Facchini, M. C., Decesari, S., Fuzzi, S., Zhou, J., Mønster, J., and Rosenørn, T.: Hygroscopic growth and critical supersaturations for mixed aerosol particles of inorganic and organic compounds of atmospheric relevance, Atmos. Chem. Phys., 6, 1937-1952, doi:10.5194/acp-6-1937-2006, 2006.

Tang, I. N. and Munkelwitz, H. R.: Composition and temperature dependence of the deliquescence properties of hygroscopic aerosol, Atmos. Environ., 27A, 467-473, doi:10.1016/09601686(93)90204-C, 1993.

Tang, I. N. and Munkelwitz, H. R.: Water activities, densities, and refractive indices of aqueous sulfates and sodium nitrate droplets of atmospheric importance, J. Geophys. Res., 20, 18801-18808, 1994.

Tong, C., Clegg, L. C., and Seinfeld, J. H.: Comparison of activity coefficient models for atmospheric aerosols containing mixtures of electrolytes, organics, and water, Atmos. Environ., 42, 54595482, 2008.

Topping, D. O., McFiggans, G. B., and Coe, H.: A curved multicomponent aerosol hygroscopicity model framework: Part 1 - Inorganic compounds, Atmos. Chem. Phys., 5, 1205-1222, doi:10.5194/acp-5-1205-2005, 2005a.

Topping, D. O., McFiggans, G. B., and Coe, H.: A curved multicomponent aerosol hygroscopicity model framework: Part 2 - Including organic compounds, Atmos. Chem. Phys., 5, 1223-1242, doi:10.5194/acp-5-1223-2005, 2005b.

Virtanen, A., Rönkkö, T., Kannosto, J., Ristimäki, J., Mäkelä, J. M., Keskinen, J., Pakkanen, T., Hillamo, R., Pirjola, L., and Hämeri, K.: Winter and summer time size distributions and densities of traffic-related aerosol particles at a busy highway in Helsinki, Atmos. Chem. Phys., 6, 2411-2421, doi:10.5194/acp-6-2411-2006, 2006.

Wang, Z., King, S. M., Freney, E., Rosenoern, T., Smith, M. L., Chen, Q., Kuwata, M., Lewis, E. R., Pöschl, U., Wang, W., Buseck, P. R., and Martin, S. T.: The Dynamic Shape Factor of Sodium Chloride Nanoparticles as Regulated by Drying Rate, Aerosol Sci. Technol., 44, 939-953, doi:10.1080/02786826.2010.503204, 2010.

Wex, H., Stratmann, F., Hennig, T., Hartmann, S., Niedermeier, D., Nilsson, E., Ocskay, R., Rose, D., Salma, I., and Ziese, M. Connecting hygroscopic growth at high humidities to cloud activation for different particle types, Environ. Res. Lett., 3, 1-10, doi:10.1088/1748-9326/3/3/035004, 2008.

Wexler, A. S. and Clegg, S. L.: Atmospheric aerosol models for systems including the ions $\mathrm{H}^{+}, \mathrm{NH}_{4}+, \mathrm{Na}^{+}, \mathrm{SO}_{4}^{2-}, \mathrm{NO}_{3}^{-}, \mathrm{Cl}^{-}$, $\mathrm{Br}^{-}$, and $\mathrm{H}_{2} \mathrm{O}$, J. Geophys. Res., 107, ACH 14-1-ACH 14-14, doi:10.1029/2001JD000451, 2002.

Wexler, A. S. and Seinfeld, J. H.: Second-generation inorganic aerosol model, Atmos. Environ., 25A, 2731-2748, doi:10.1016/0960-1686(91)90203-J, 1991. 
Yeung, M. C. and Chan, C. K.: Water content and phase transitions in particles of inorganic and organic species and their mixtures using micro-Raman spectroscopy, Aerosol Sci. Technol., 44, 269-280, 2010.

Yeung, M. C., Lee, A. K. Y., and Chan, C. K.: Phase transition and hygroscopic properties of internally mixed ammonium sulfate and adipic acid (AS-AA) particles by optical microscopic imaging and Raman spectroscopy, Aerosol Sci. Technol., 43, 387399, 2009.

Zardini, A. A., Sjogren, S., Marcolli, C., Krieger, U. K., Gysel, M., Weingartner, E., Baltensperger, U., and Peter, T.: A combined particle trap/HTDMA hygroscopicity study of mixed inorganic/organic aerosol particles, Atmos. Chem. Phys., 8, 55895601, doi:10.5194/acp-8-5589-2008, 2008.
Zuend, A., Marcolli, C., Luo, B. P., and Peter, T.: A thermodynamic model of mixed organic-inorganic aerosols to predict activity coefficients, Atmos. Chem. Phys., 8, 4559-4593, doi:10.5194/acp8-4559-2008, 2008.

Zuend, A., Marcolli, C., Booth, A. M., Lienhard, D. M., Soonsin, V., Krieger, U. K., Topping, D. O., McFiggans, G., Peter, T., and Seinfeld, J. H.: New and extended parameterization of the thermodynamic model AIOMFAC: calculation of activity coefficients for organic-inorganic mixtures containing carboxyl, hydroxyl, carbonyl, ether, ester, alkenyl, alkyl, and aromatic functional groups, Atmos. Chem. Phys., 11, 9155-9206, doi:10.5194/acp11-9155-2011, 2011. 